\title{
Revisão das espécies de Stylogaster Macquart do grupo stylata com descrição de uma espécie nova do Brasil (Diptera, Conopidae, Stylogasterinae)
}

\author{
Leonardo Silvestre Gomes Rocha ${ }^{1} \&$ Cátia Antunes de Mello-Patiu ${ }^{1}$
} 'Departamento de Entomologia, Museu Nacional/Universidade Federal do Rio de Janeiro, Quinta da Boa Vista, s/nº, $20940-040$ São Cristóvão,
Rio de Janeiro-RJ, Brasil. ghelfo@ @otmail.com; catiapatiu@ oi.com.br

\begin{abstract}
Revision of the Brazilian species of Stylogaster Macquart from stylata group, with description of a new species from Brazil (Diptera, Conopidae, Stylogasterinae). The Brazilian species of Stylogaster Macquart, 1835 from the stylata group are studied and redescribed in detail: Stylogaster brasilia Camras \& Parrillo, 1985, S. dispar Camras \& Parrillo, 1985, S. longispina Camras \& Parrillo, 1985, S. rafaeli Camras \& Parrillo, 1996, S. souzai Monteiro, 1960, and S. stylata (Fabricius, 1805). A new species from Brazil, Rio de Janeiro - S. fluminensis sp. nov., is described and compared with S. stylosa Townsend, 1897, which is also redescribed based on type material. Diagnosis, keys for identification, geographic distributions and illustrations are also provided.
\end{abstract}

KEYWORDS. Conopidae; Diptera; morphology; taxonomy.

RESUMO. Revisão das espécies brasileiras de Stylogaster Macquart do grupo stylata, com descrição de uma espécie nova do Brasil (Diptera, Conopidae, Stylogasterinae). As espécies brasileiras de Stylogaster Macquart, 1835 do grupo stylata são detalhadamente estudadas e redescritas: Stylogaster brasilia Camras \& Parrillo, 1985, S. dispar Camras \& Parrillo, 1985, S. longispina Camras \& Parrillo, 1985, S. rafaeli Camras \& Parrillo, 1996, S. souzai Monteiro, 1960, and S. stylata (Fabricius, 1805). Uma nova espécie do Brasil, Rio de Janeiro - S. fluminensis sp. nov., é descrita e comparada com S. stylosa Townsend, 1897, redescrita com base no material-tipo. Diagnoses, chaves de identificação, distribuição geográfica e ilustrações são também fornecidas.

PALAVRAS-CHAVE. Conopidae; Diptera; morfologia; taxonomia.

Conopidae é uma família pouco estudada entre os Diptera Acalyptratae e, segundo a classificação proposta por Hennig (1973) e seguida por McAlpine (1981), está incluída em uma superfamília própria, Conopoidea. São dípteros alongados e esguios, que geralmente mimetizam vespas; os adultos são nectarívoros e apresentam probóscide bem desenvolvida, enquanto as larvas são endoparasitos obrigatórios de outros insetos (Smith \& Peterson 1987). São reconhecidas atualmente cerca de 800 espécies em 45 gêneros, distribuídas por todas as regiões biogeográficas.

O gênero Stylogaster Macquart, 1835 está presente em todas as regiões biogeográficas, exceto a Paleártica. É predominante na região Neotropical, onde está representado por 69 espécies e pode ser diagnosticado por apresentar uma quilha mediana na faciália, probóscide longa e biarticulada, com labelos filiformes, olhos com as facetas medianas mais desenvolvidas que as demais, fêmeas com ovipositor muito alongado, com processos laterais no esternito 8 e ovos com espinhos recurrentes. Diferentemente dos outros membros da família, as espécies de Stylogaster têm preferência por insetos das ordens Orthoptera, Blattaria e Diptera caliptrados para depositarem seus ovos. São frequentemente vistos em associação com formigas-de-correição (Hymenoptera: Formicidae: Ecitoninae), espreitando os insetos que fogem dos exércitos de formigas para neles realizarem a oviposição (Lopes 1937, Smith \& Peterson 1987, Kotrba 1997).

A primeira espécie do gênero foi descrita por Fabricius (1805), ainda como Conops stylatus. Macquart (1835) propôs o gênero Stylogaster para abrigar C. stylatus, reconhecendo a grande diferença entre este e os demais táxons da família. Kröber (1919), em seu catálogo da família, propôs a subfamília Stylogasterinae, contendo somente o gênero Stylogaster. A partir daí, vários autores, como Willinston (1883), Townsend (1897) e Aldrich (1930), acrescentaram espécies ao gênero. Lopes (1937) apresentou uma revisão da morfologia, ilustrou algumas espécies já descritas, descreveu quatro espécies novas do Brasil e fez observações sobre a biologia do gênero. Contribuindo também com o conhecimento das espécies brasileiras, Monteiro (1960) coletou extenso material na Amazônia e descreveu uma espécie nova, S. souzai. Camras $(1957,1963,1965,1967,1989,1990,1992,2004)$ e Camras \& Parrillo $(1985,1996)$ descreveram várias espécies novas das Américas e Papavero (1971) publicou o catálogo dos Conopidae neotropicais, listando 42 espécies no gênero Stylogaster.

Camras \& Parrillo (1985) agruparam as espécies do Novo Mundo com base em caracteres morfológicos, reconhecendo quatro grupos de espécies, a saber: grupo stylata, grupo neglecta, grupo ornatipes e grupo rectinervis. O grupo 
stylata foi considerado pelos autores como o mais "primitivo", reunindo 16 espécies neotropicais, seis delas ocorrendo no Brasil, a saber: Stylogaster brasilia Camras \& Parrillo, 1985, S. dispar Camras \& Parrillo, 1985, S. longispina Camras \& Parrillo, 1985, S. rafaeli Camras \& Parrillo, 1996, S. souzai Monteiro, 1960 e S. stylata (Fabricius, 1805). Neste mesmo trabalho, os autores afirmaram que S. stylosa Townsend, 1897 tem distribuição restrita aos E. U. A. e México, e que todos os exemplares de procedência ao sul do México, consequentemente incluindo o Brasil, correspondiam a identificações errôneas, possivelmente, novas espécies. Os autores não utilizaram nenhuma metodologia para dividir o gênero em grupos de espécies, nem para afirmar que o grupo stylata é o mais basal, portanto não há indicação segura de que os grupamentos propostos representem táxons monofiléticos.

Enfocando a taxonomia dos Stylogaster, este trabalho objetiva apresentar a revisão das seis espécies do grupo stylata que ocorrem no Brasil, incluindo um estudo detalhado da morfologia, especialmente das terminálias masculina, feminina e dos ovos. Além disso, inclui a redescrição e ilustração do material-tipo de S. stylosa, visando esclarecer o problema relativo aos exemplares sul-americanos. Após tal análise, exemplares procedentes do Rio de Janeiro, previamente identificado como S. stylosa e representados na coleção do Museu Nacional (Rio de Janeiro, Brasil), foram reconhecidos como uma nova espécie do grupo stylata, cuja descrição é também apresentada.

\section{MATERIALE MÉTODOS}

As coleções depositárias são referidas no texto pelas seguintes abreviaturas:

CNC - Canadian National Collection, Ottawa, Canadá.

BMNH - The Natural History Museum, Londres, Inglaterra.

INPA - Instituto Nacional de Pesquisas da Amazônia, Manaus, Brasil.

MNRJ - Museu Nacional/UFRJ, Rio de Janeiro, Brasil.

ZMUC - The Natural History Museum of Denmark, Copenhagen, Dinamarca.

Para preparação dos exemplares, os abdomes foram retirados e tratados sequencialmente com $\mathrm{KOH} 10 \%$, água destilada, ácido acético, água destilada, álcool 70\% e glicerina. Abdomes, terminálias e ovos, após dissecção e tratamento, foram montados em lâminas provisórias, observados e desenhados em estereomicroscópio Wild M-5 e/ou microscópio óptico Zeiss MC 80, ambos com câmara-clara. Os ovos foram obtidos do interior do abdome das fêmeas examinadas. Após estudo, o material dissecado foi depositado em micro-tubo plástico com glicerina, guardado junto ao exemplar correspondente.

A chave de identificação inclui caracteres de macho e de fêmea, exceto para S. rafaeli e S. souzai, cujas fêmeas ainda são desconhecidas. Uma descrição detalhada é fornecida para S. brasilia e descrições comparativas para as demais espécies, apresentadas em ordem alfabética. Entretanto, para S. stylata e $S$. dispar são fornecidas apenas as diagnoses e algumas ilustrações que possibilitem a comparação e diferenciação das demais, uma vez que estas espécies foram recentemente redescritas (Mello-Patiu \& Rocha 2003; Rocha \& Mello-Patiu 2004).

A terminologia adotada foi aquela de McAlpine (1981), exceto para descrição da terminália da fêmea e para o ovo, para os quais se usou Kotrba (1997). Os estados brasileiros são referidos, na distribuição geográfica registrada e na chave, por suas abreviaturas-padrão.

\section{RESULTADOS}

\section{Gênero Stylogaster Macquart, 1835}

Stylogaster Macquart, 1835: 38. Espécie-tipo: Conops stylatus Fabricius, 1805 (por monotipia).

Stylomyia Westwood, 1852: 268. Espécie-tipo: Stylomyia leonum Westwood (Coquillett, 1910: 610).

Diagnose: Moscas pequenas, esguias e alongadas, com aparência de vespas; 3 pequenas cerdas orbitais e 2 cerdas frontais; faciália em forma de quilha longitudinal; probóscide longa e articulada na base e na porção mediana; labelos filiformes; olhos com facetas medianas mais desenvolvidas que as demais; tórax com 1 cerda proepisternal, 1 dorsocentral pós-sutural, 1 notopleural, 1 supra-alar, 1 anepimeral, 2 pósalares e 1 par de escutelares divergentes, todas pretas com exceção da proepisternal clara; tíbias médias com uma fileira de cerdas em forma de pente na face ventral; abdome com esternitos totalmente membranosos; tergito $2 \mathrm{com}$ fileira transversal de 5 a 7 cerdas fortes; machos com parâmeros fusionados ao hipândrio e com cerdas numerosas na margem posterior; fêmeas com ovipositor muito alongado em relação aos outros Conopidae; terminália feminina com cercos, placas subanais e apêndices terminais alongados, formando guias para os ovos e não estruturas de perfuração; ovos com 2 a 4 espinhos recurrentes, extremidade posterior esclerosada e pontiaguda e bolsa membranosa extrusível.

\section{Grupo stylata (sensu Camras \& Parrillo 1985)}

Diagnose: Ovipositor e triângulo ocelar curtos; triângulo ocelar não atingindo a base das antenas; cerdas pós-pronotais ausentes; antenas com escapo e pedicelo de comprimentos similares.

Chave para identificação das espécies brasileiras de Stylogaster Macquart, 1835 do grupo stylata

1. Arista com 2 artículos no macho (Fig. 54) e 1 na fêmea (Fig. 55); coxa protorácica com cerdas claras nas faces anterior e posterior; esternito 5 do macho com profunda reentrância mediana e cerdas em toda a extensão (Fig. 56); esternito 8 da fêmea com profunda reentrância mediana ventral e com 2 lobos terminais laterais (Figs. 8, 
59) [Brasil (AP, PA, MT, RJ, SC), Equador, Colômbia, Paraguai, Argentina] Stylogaster stylata (Fabricius, 1805)

Arista com 3 artículos em machos e fêmeas; coxa protorácica somente com cerdas pretas; esternito 5 do macho e esternito 8 da fêmea de outra forma 2

2. Esternito 5 do macho sem protuberâncias (Fig. 52) ............ 3 Esternito 5 do macho com protuberância que se estende do centro até a margem posterior (Figs. 13, 23, 35, 46) ....... 4

3. Fronte castanho-escura, incluindo o triângulo ocelar, que apresenta a mesma cor em toda a extensão; veia $M_{1+2}$ encontrando-se com $\mathrm{R}_{4+5}$ antes da costa (Fig. 51); tergito 5 do macho com cerdas pretas e cerdas claras; cercos com cerdas pretas (Fig. 53); fêmea desconhecida [Brasil (AP, PA)] ................ Stylogaster souzai Monteiro, 1960.

Fronte castanha, com áreas mais claras ao redor da base das antenas; triângulo ocelar também castanho, mas com a região central mais escura; veia $\mathrm{M}_{1+2}$ encontrando-se com $\mathrm{R}_{4+5}$ bem próximo à costa (Fig. 4); tergito 5 do macho somente com cerdas pretas; cercos com cerdas claras e cerdas pretas (Fig.5); esternito 8 das fêmeas com reentrância mediana ventral em forma de W (Fig. 8) e com apêndices laterais fortemente curvos (Figs. 6, 8) [Brasil (RO, BA, RJ, SP)] Stylogaster brasilia Camras \& Parrillo, 1985

4. Faciália com sulco transversal (Fig. 11); $\mathrm{M}_{1+2}$ encontrandose com $\mathrm{R}_{4+5}$ bem antes da costa (Fig. 12); edeago sem projeções agudas (Fig. 14); esternito 8 da fêmea sem reentrância mediana ventral e com apêndices laterais dobrados a $90^{\circ}$ para dentro (Fig. 16) [Brasil (PA, RO), Equador, Peru]

Stylogaster dispar Camras \& Parrillo, 1985.

Faciália sem sulco transversal; $\mathrm{M}_{1+2}$ encontrando-se com $\mathrm{R}_{4+5}$ bem próximo à costa; edeago com projeções agudas apicais (Figs. 24, 36, 47); esternito 8 das fêmeas com reentrância mediana ventral em $\mathrm{V}$ e com apêndices laterais suavemente curvos (Figs. 28, 39) ... 5

5. Triângulo ocelar com a extremidade anterior arredondada (Fig. 18); trocânter e fêmur posteriores com cerdas longas na face interna; esternito 5 do macho com fraca protuberância central e com aba membranosa contornando a margem posterior (Fig. 23); edeago com uma projeção apical dirigida para frente (Fig. 24); tergito 9 da fêmea com projeção apical pontiaguda entre os cercos (Fig. 27) [Brasil (RJ)]

Stylogaster fluminensis sp. nov.

Triângulo ocelar com a extremidade anterior pontiaguda

(Figs. 31, 42); demais caracteres de outra forma ........... 6

6. Triângulo ocelar castanho-escuro em toda a extensão; esternito 5 do macho com protuberância em forma de $\mathrm{Ye}$ com cerdas pretas (Fig. 35); parâmero quase do mesmo tamanho do edeago, com densa fileira de cerdas na margem posterior; edeago com duas projeções apicais dirigidas para frente (Fig. 36); esternito 8 da fêmea com pequena reentrância ventral em forma de $\mathrm{V}$ e com apêndices laterais levemente curvos [Brasil (AC), Peru, Bolívia] ... Stylogaster longispina Camras \& Parrillo, 1985

Triângulo ocelar com uma região castanha entre os ocelos, mais escura que o restante do triângulo; esternito 5 do macho com protuberância curta, aproximadamente retangular, na margem posterior, e com denso tufo de cerdas pretas longas (Fig. 46); parâmero mais curto que o edeago, com cerdas na margem posterior; edeago com quatro projeções: duas mediais dirigidas para frente e duas apicais (Fig. 47); fêmea desconhecida [Brasil (RO)] . Stylogaster rafaeli Camras \& Parrillo, 1996

\section{Stylogaster brasilia Camras \& Parrillo, 1985}

(Figs. 1-10)

Stylogaster brasilia Camras \& Parrillo, 1985: 113. Localidade-tipo: Brasil, Rio de Janeiro, Represa do Rio Grande; Holótipo macho (CNC). Ref. - Camras \& Parrillo 1996.

Diagnose: Cerda proepisternal preta; machos com esternito 5 sem reentrância, com uma pequena borda saliente e com cerdas pretas esparsas; terminália da fêmea apresentando esternito $8 \mathrm{com}$ suave reentrância mediana ventral em forma de $\mathrm{W}$ no ápice do esternito 8 e com lobo terminal lateral em forma de gancho; ovos com extremidade posterior pontiaguda e espinhos recurrentes divergentes, acompanhando a borda do cório.

\section{Macho}

Coloração: Notopleura castanho-clara a amarela; escuto castanho-escuro, com três faixas castanho-claras: duas laterais estendendo-se até os calos pós-alares e uma mediana mais curta, estendendo-se até pouco antes da sutura; escutelo e calos pós-alares castanho-claros (Fig.3); anepisterno castanho-claro, demais escleritos pleurais amarelos; halter castanho-claro com ápice escuro (Fig.3); pernas com coloração predominantemente amarela, exceto o par metatorácico castanho com faixa transversal amarela no fêmur; abdome com tergito 1 castanho na região dorsal; tergito $2 \mathrm{com}$ mancha dorsal de cor castanha em forma de T; tergitos 3 e 4 castanhos com grande mancha arredondada amarela na margem inferior; tergito 5 com mancha dorsal de cor castanha em forma de T; sintergosternito 6+7+8 e epândrio castanhos. Cabeça: Parátipo examinado sem cabeça, porém, segundo Camras \& Parrillo (1985), o macho apresenta vértice preto, incluindo o triângulo ocelar, fronte preta com margem anterior castanha; pálido nas margens; faciália e gena amarelas com polinosidade clara; antena de amarela a marrom; $3^{\circ}$ artículo preto dorsal e apicalmente; arista preta (ver comentários). Tórax: Lobos pós-pronotais sem cerdas; 1 cerda proepisternal, 1 notopleural, 1 supra-alar, 1 anepisternal, 2 pós-alares, 1 dorso-central pós-sutural, 1 escutelar, todas pretas (Fig. 3); pernas com cerdas pretas curtas, exceto pelo par posterior, que apresenta longas cerdas 

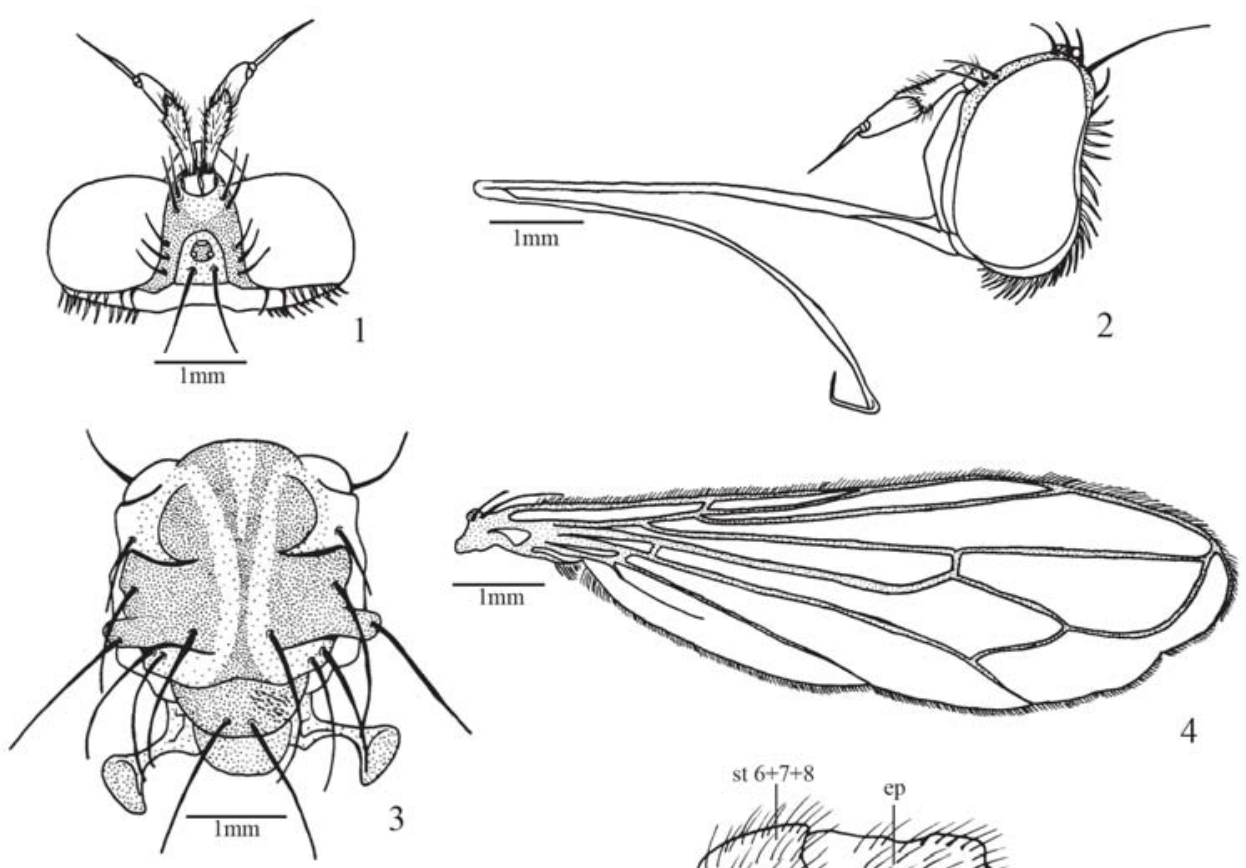

4
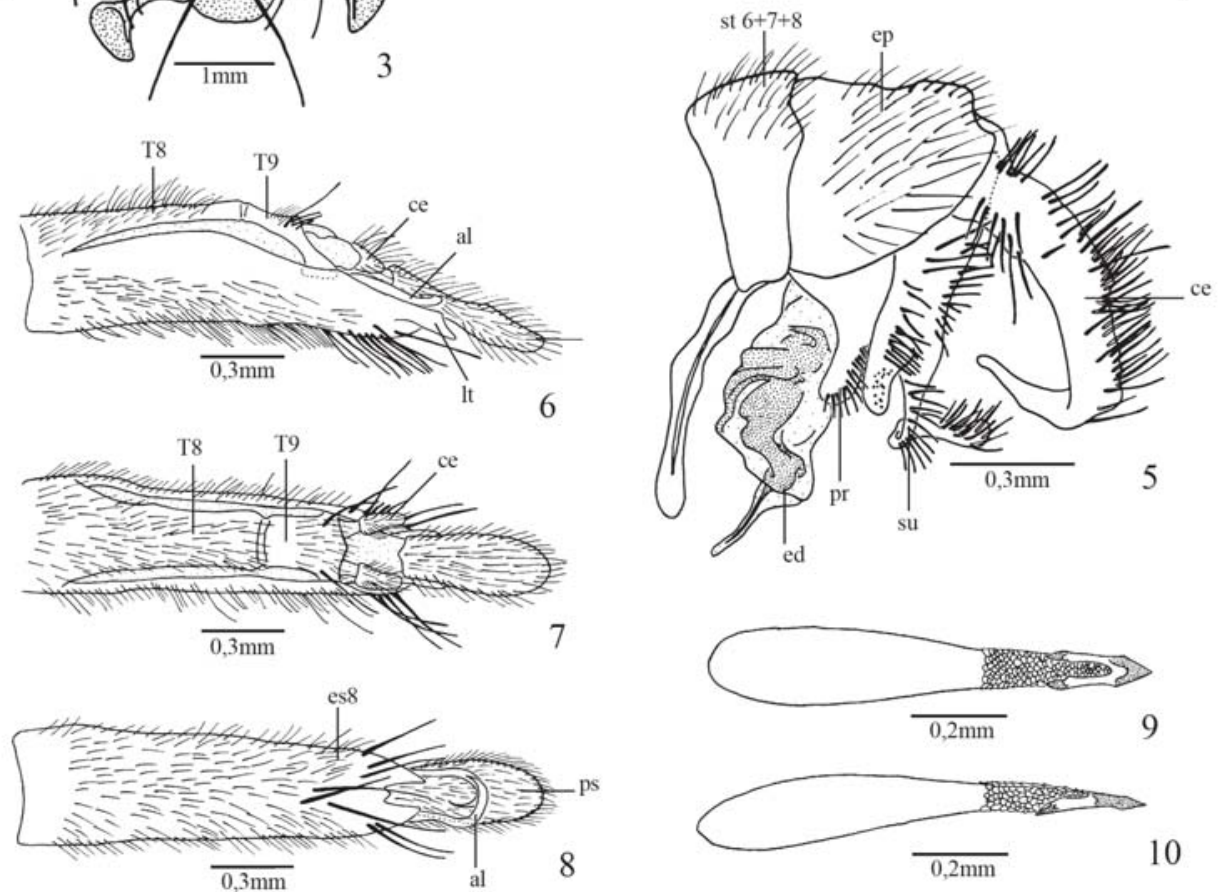

Fig. 1. Stylogaster brasilia Camras \& Parrillo. cabeça, fêmea, vista dorsal; fig.2: cabeça, fêmea, vista lateral; fig.3: macho, tórax, vista dorsal; fig.4: asa; fig. 5: terminália masculina, vista lateral; fig. 6: terminália feminina, vista lateral; fig. 7: terminália feminina, vista dorsal; fig. 8: terminália feminina, vista ventral; fig. 9: ovo, vista ventral; fig. 10: ovo, vista lateral $(\mathrm{al}=$ apêndice lateral do esternito 8; ce= cerco; ed= edeago; ep= epândrio; es= esternito; $1 \mathrm{t}=$ lobo lateral do esternito $8 ; \mathrm{pr}=$ parâmero; $\mathrm{ps}=$ placa subanal; st= sintergosternito; su= surstilo; $\mathrm{T}=$ tergito) .

pretas em sua face ventral; coxa com cerdas pretas nas faces anterior e posterior; tíbia média com esporões pretos; asas hialinas com $\mathrm{M}_{1+2}$ apresentando forte curvatura, encontrandose com $\mathrm{R}_{4+5}$ antes do ápice (Fig. 4). Abdome: Tergito 1 com um sulco na região lateral e cerdas na parte inferior; tergito $5 \mathrm{com}$ cerdas pretas fortes dirigidas para trás na margem posterior; esternitos com alguma pilosidade; esternito 5 arredondado, com algumas cerdas pretas dirigidas para trás próximo à base. Terminália: Sintergosternito $6+7+8$ bem demarcado, estreito, com cerca da metade da largura epândrio em sua linha média dorsal; epândrio grande, sem cerdas fortes; cercos com cerdas pretas e claras na margem posterior e somente pretas na margem anterior; surstilos com dois lobos: o anterior com pequenos espinhos pretos na face interna e cerdas pretas na face externa, e o posterior com cerdas pretas na base e pretas e claras no ápice; parâmeros com cerdas pretas apicais; edeago com endofalo castanho e uma projeção membranosa pontiaguda no ápice (Fig. 5).

Fêmea. Semelhante ao macho, exceto pelos seguintes caracteres:

Coloração: Fronte castanho-escura, exceto a área castanho- 

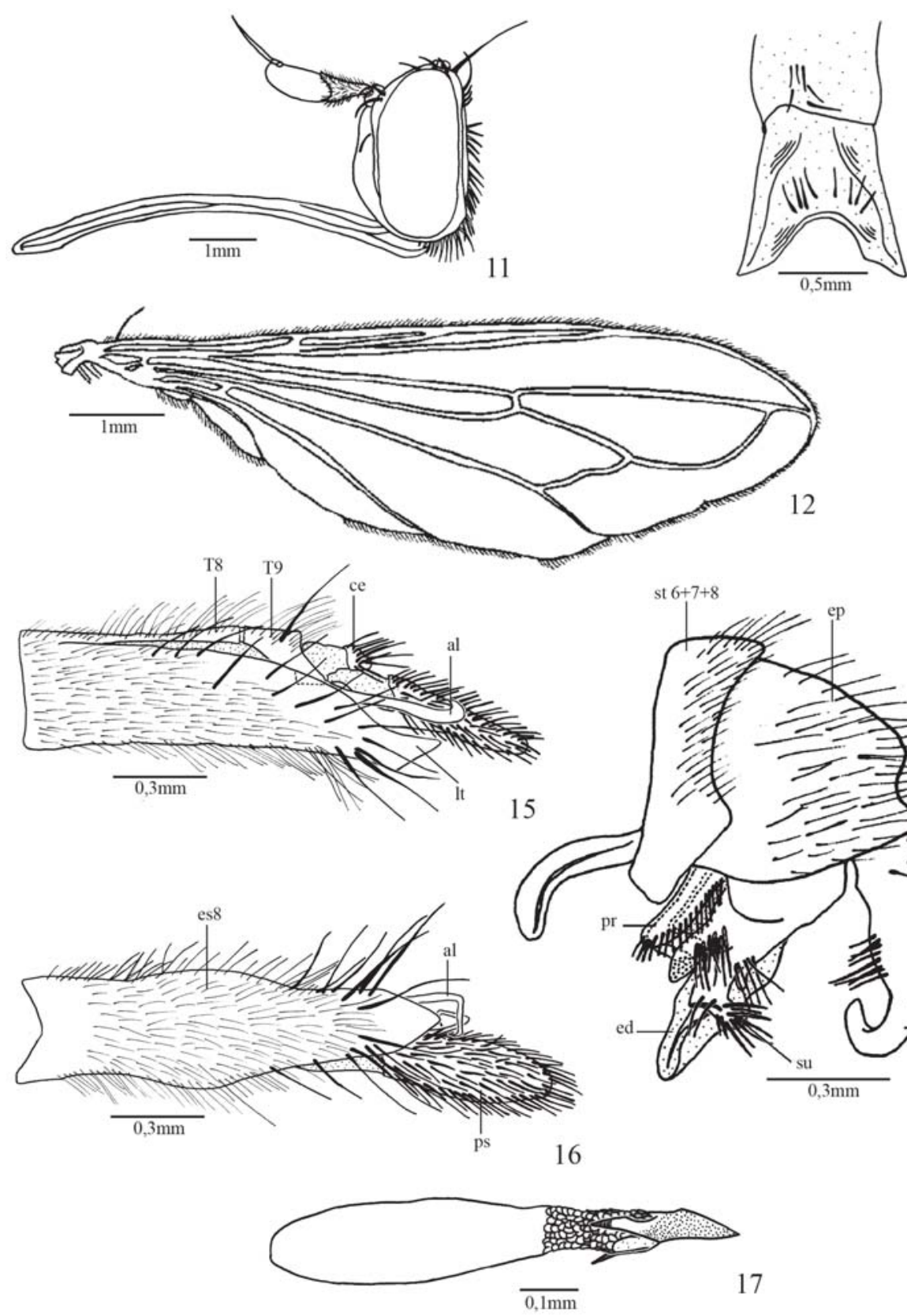

Fig. 11. Stylogaster dispar Camras \& Parrillo. cabeça, macho, vista lateral; fig. 12: asa; fig.13: esternito 5, macho; fig. 14: terminália masculina, vista lateral; fig. 15: terminália feminina, vista lateral; fig. 16: terminália feminina, vista ventral; fig. 17: ovo, vista látero-ventral (al= apêndice lateral do esternito 8 ; $\mathrm{ce}=$ cerco; $\mathrm{ed}=$ edeago; $\mathrm{ep}=$ epândrio; es= esternito; lt= lobo lateral do esternito 8 ; pr= parâmero; ps= placa subanal; st= sintergosternito; su= surstilo; $\mathrm{T}=$ tergito).

clara ao redor da lúnula; triângulo ocelar mais claro que a fronte, exceto entre os ocelos (Fig. 1); faciália prateada; escapo e pedicelo castanho-claros, flagelo castanho-escuro; escuto castanho, com duas faixas claras em quase toda a extensão; tergitos 2 a 4 com mancha dorsal castanha em forma de T; tergito 5 com a região dorsal castanha; tergito 6 amarelo; tergito 7 amarelo com mancha dorsal castanha; esternito 8, placa subanal e cercos castanhos com ápice amarelo. Cabeça: Triângulo ocelar curto, com extremidade arredondada (Fig. 1); pedicelo com cerdas nas faces dorsal e ventral; flagelo pouco menor que o pedicelo (Fig. 2); cerdas genais claras. Tórax: Tíbia média sem esporão; fêmur posterior sem cerdas longas na face ventral. Abdome: Cerdas pretas e claras no tergito 1 . Terminália: esternito 8 com cerdas fortes ventrais e reentrância mediana em forma de $\mathrm{W}$ no ápice, apêndices laterais em forma de gancho e lobo terminal lateral destacado; cercos longos e retos (Figs. 6, 7, 8).

Ovos. Cório translúcido; terço posterior recoberto por pequenas escamas intrincadas; extremidade posterior castanho-escura, pontiaguda e naviforme; espinhos laterais 
com o ápice castanho-escuro, pouco divergentes, acompanhando o contorno do cório; sem orifício aparente entre os espinhos (Figs. 9, 10).

Distribuição: Brasil (RO, BA, RJ, SP).

Material examinado: BRASIL: Rio de Janeiro, Rio de Janeiro, Represa do Rio Grande [Floresta da Tijuca], XII.1969, M. Alvarenga (Malaise), 2 fêmeas parátipos (CNC); São Paulo, Salesópolis, Est[ação] Biológica Boracéia, 14-19.X.1970, J. W. Boyes \& J. H. Guimarães, 1 macho parátipo (CNC).

Comentários: Embora o macho examinado estivesse sem cabeça, consideramos que deva ser semelhante à fêmea com relação à coloração e às características da fronte e do triângulo ocelar, uma vez que não foi verificado dimorfismo sexual em relação à cabeça em qualquer outra espécie do gênero, exceto na antena.

\section{Stylogaster dispar Camras \& Parrillo, 1985}

(Figs. 11-17)

Stylogaster dispar Camras \& Parrillo, 1985: 112. Localidade-tipo: Peru, Avispas, Madre de Dios. Holótipo macho (CNC). Ref. Camras \& Parrillo 1996.

Diagnose: Fronte castanho-escura em toda a extensão, exceto por uma mancha amarela arredondada à frente do triângulo ocelar e uma estreita faixa da mesma cor ao redor da lúnula; fêmeas com polinosidade prateada em forma de coração na região entre os ocelos; Sulco transversal no terço superior da faciália (Fig. 11); cerda proepisternal clara; asas com $\mathrm{M}_{1+2}$ fortemente curva, encontrando-se com $\mathrm{R}_{4+5}$ antes do ápice da asa (Fig. 12); esternito 5 do macho com cerdas pretas voltadas para frente e distintamente separado do 4 (Fig. 13); terminália do macho apresentando cercos com ápice em gancho e cerdas pretas fortes nas faces anterior e posterior; surstilos com três lobos, o posterior com uma fileira de cerdas pretas reclinadas, o mediano dobrado para dentro com cerdas pretas na base e cerdas claras no ápice, e o anterior, com uma fileira de cerdas claras na face externa e diminutos espinhos pretos na face interna; edeago membranoso com endofalo terminando em anel e acrofalo em forma de espinho (Fig. 14); terminália da fêmea apresentando esternito 8 com ápice pontiagudo sem reentrância mediana ventral e lobo terminal lateral único (Fig. 15) e apêndices laterais dobrados a $90^{\circ}$ (Fig. 16); ovos com espinho terminal grande e pontiagudo, com um orifício recoberto por membrana entre os espinhos laterais divergentes (Fig. 17).

Distribuição: Brasil (PA, RO), Equador, Peru.

Material examinado: PERU: Avispas, Madre de Dios, 400 m., 1020IX.1962, L. Peña, 2 fêmeas parátipos (CNC); Cuzco, Quincemil, 700 m., 1-15.XI.1962, L. Peña, 1 macho parátipo (CNC). EQUADOR: Pastaza, Pompeya, Rio Napo, 14-22.V.1965, L. Peña, 1 macho parátipo (CNC).

Comentários: Rocha \& Mello-Patiu (2004) redescreveram esta espécie e forneceram ilustrações detalhadas da cabeça, tórax, abdome, terminália masculina e feminina e ovo.
Relacionaram a espécie à S. stylata (Fabricius) e $S$. rafaeli Camras \& Parrillo.

\section{Stylogaster fluminensis sp. nov.} (Figs. 18-30)

Stylogaster fluminensis Rocha \& Mello-Patiu. Localidade-tipo: Brasil, Rio de Janeiro, Alto da Boa Vista. Holótipo macho (MNRJ).

Diagnose: Coxa e trocânter posteriores com cerdas longas na face interna; pequeno tufo de cerdas acima da cerda anepimeral; esternito 5 do macho com aba membranosa marginal e com leve protuberância central; terminália da fêmea apresentando tergito 9 com projeção pontiaguda apical entre os cercos e cercos com pilosidade na região membranosa basal.

Macho. Difere de $S$. brasilia pelos seguintes caracteres:

Coloração: Fronte castanho-escura, margem da lúnula castanho-clara; triângulo ocelar castanho-claro com tubérculo central castanho-escuro; faciália amarela com polinosidade dourada; escapo amarelo, pedicelo com polinosidade dourada, flagelo castanho-claro (Figs. 18,19); notopleura amarela; escuto castanho-escuro com faixa longitudinal castanho-clara ao centro (Fig.20); pernas anterior e média com tarsos castanhoclaros, coxa posterior castanho-clara; fêmur posterior amarelo com duas faixas transversais castanho-claras; tíbia posterior amarela com o ápice castanho-claro; tarso castanho-claro; tergitos 2, 3 e 4 com mancha de cor castanha dorsal em forma de T; tergito 5 castanho, com margem ventral clara; sintergosternito 6+7+8 e epândrio castanho-claros (Fig. 22). Cabeça: Triângulo ocelar com limites bem definidos, chegando até a metade da fronte e com a ponta arredondada; 4 cerdas orbitais do lado esquerdo, 3 do lado direito (Fig. 18); protuberância frontal grande; pedicelo levemente curvado na base, de tamanho semelhante ao flagelo (Figs. 18, 19). Tórax: Cerda proepisternal clara; escuto com pequena protuberância central anterior e duas protuberâncias arredondadas laterais a esta; pequenas projeções com cerdas logo acima da inserção da cerda anepimeral (Fig. 20); trocânter e fêmur posterior com cerdas longas; tíbia anterior com esporão claro; asas com veia $\mathrm{R}_{4+5}$ encontrando-se com $\mathrm{M}_{1+2}$ pouco acima do ápice; $\mathrm{M}_{1+2}$ fortemente curva; $\mathrm{A}_{2}$ nítida (Fig. 21). Abdome: Tergito $1 \mathrm{com}$ cerdas claras e pretas (Fig.22); esternitos 2-4 membranosos, com poucas cerdas pretas; esternito 5 com limite bem definido, com cerdas pretas e com fraca protuberância central, margem posterior em U contornada por aba membranosa (Fig. 23). Terminália: Epândrio densamente piloso; cercos largos com o ápice curvado medialmente e com cerdas pretas e claras; surstilos com lobo anterior apresentando pequenas cerdas pretas na face interna e o posterior com cerdas longas claras e pretas; parâmeros mais curtos que o edeago; edeago membranoso, com o ápice esclerosado e projeção apical aguda (Fig. 24).

Fêmea. Semelhante ao macho, exceto pelos caracteres:

Coloração: Tergito 5 com mancha de cor castanha em forma de T; tergito $6 \mathrm{com}$ polinosidade prateada; tergito 7 castanho, 

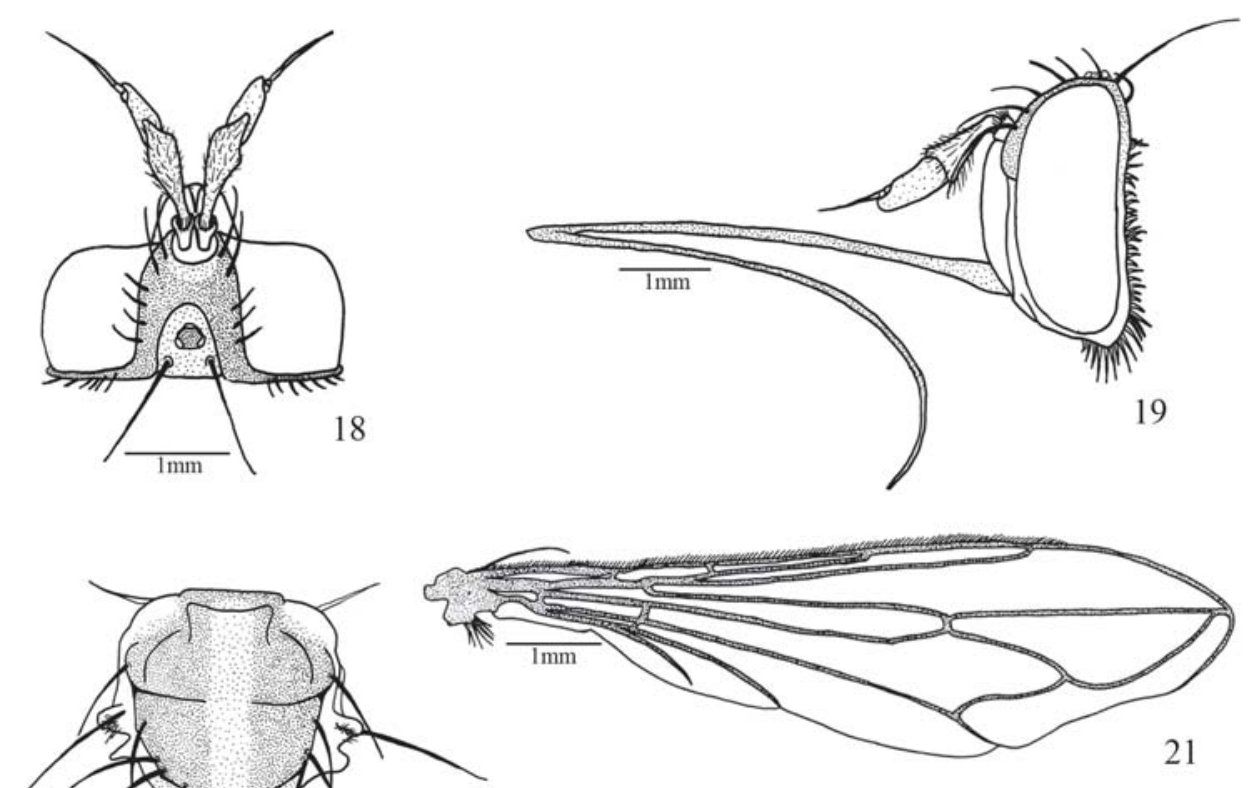

21

20
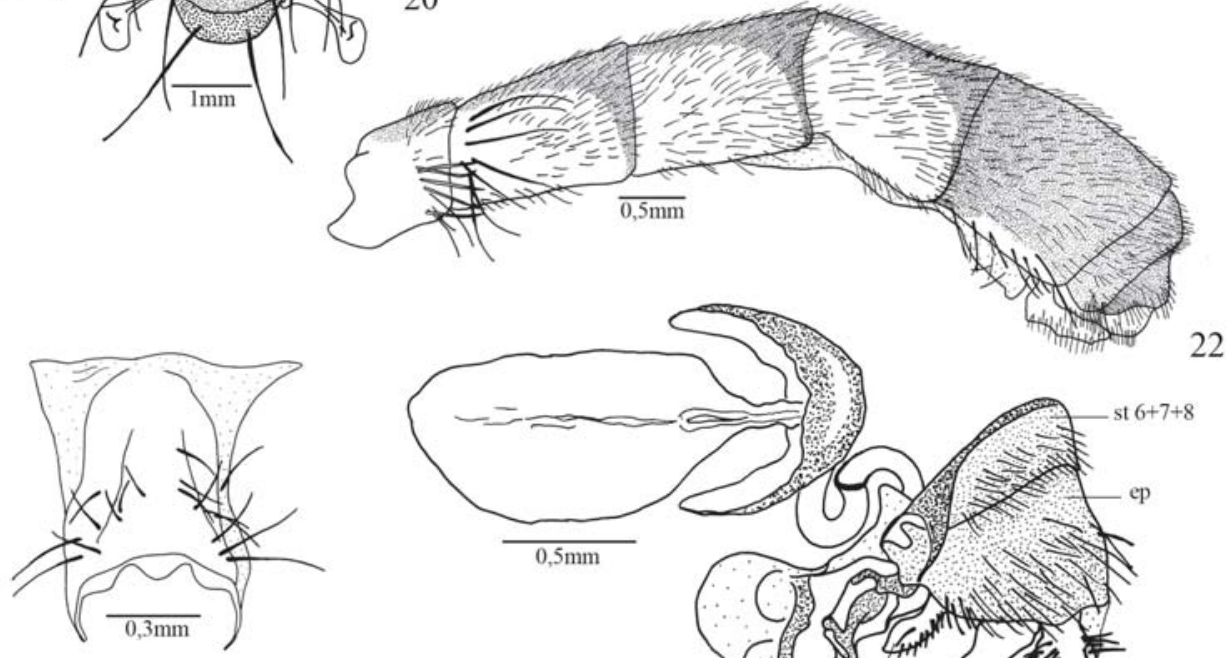

23

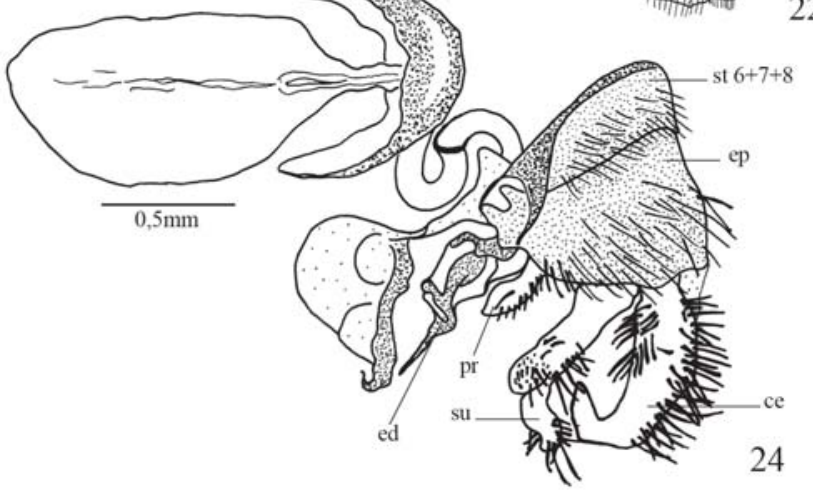

Fig. 18. Stylogaster fluminensis sp. nov. cabeça, macho, vista dorsal; fig.19: cabeça, macho, vista lateral; fig. 20: macho, tórax, vista dorsal; fig. 21: asa; fig. 22: abdome, macho, vista lateral, fig. 23: esternito 5, macho; fig. 24: terminália masculina, vista lateral (ce= cerco;ed=edeago; ep= epândrio; pr= parâmero; st= sintergosternito; su= surstilo).

ventralmente mais claro; esternito 8 castanho. Cabeça: Protuberâncias frontais pequenas. Tórax: Cerda proepisternal preta; tíbia média com esporão claro; trocânter e fêmur posterior sem cerdas longas; asa com veia $\mathrm{A}_{2}$ fraca. Abdome: Tergito 1 com cerdas pretas e claras; tergito 2 mais longo que os demais, com longas cerdas pretas laterais; tergitos 3 e 4 mais altos que largos; tergito 5 com a largura aproximadamente igual ao comprimento; todos os esternitos membranosos e sem limites definidos (Fig.25). Terminália: Tergito 6 estreito, cerca de 1/3 do comprimento do tergito 7; tergito 9 com uma área deprimida central, uma projeção dorsal aguda entre os cercos e um par de cerdas fortes laterais; esternito 8 estreito, com reentrância mediana ventral em forma de $\mathrm{V}$ na margem posterior; apêndices laterais suavemente curvos (Figs. 26, 27, 28).

Ovo. Espinho posterior sem base alargada; espinhos recurrentes paralelos ao cório, sem orifício visível entre eles (Figs. 29, 30).

Distribuição: Brasil (RJ).

Material-tipo: Holótipo macho - BRASIL: Rio de Janeiro, Rio de Janeiro, Alto da Boa Vista, IV.1966, M. Alvarenga ("Malaise trap"). Parátipos -16 machos e 3 fêmeas, mesmos dados do holótipo; 4 machos e 6 fêmeas, idem, Represa do Rio Grande [Floresta da Tijuca], I.1972. F. M. Oliveira (MNRJ). 


\section{Stylogaster longispina Camras \& Parrillo, 1985}

(Figs. 31-41)

Stylogaster longispina Camras \& Parrillo, 1985: 115. Localidadetipo: Peru, Cuzco, Quincemil. Holótipo macho (CNC). Ref. - Camras \& Parrillo, 1996.

Diagnose: Protuberâncias frontais pouco desenvolvidas; $\mathrm{M}_{1+2}$ suavemente curva, encontrando-se com $\mathrm{R}_{4+5}$ bem próximo ao ápice da asa; esternito 5 do macho com uma protuberância centro-marginal em forma de $\mathrm{Y}$, com cerdas dirigidas para a frente próximo à margem posterior; terminália da fêmea apresentando esternito $8 \mathrm{com}$ pequena reentrância mediana ventral em forma de $\mathrm{V}$ no ápice e lobo terminal lateral levemente curvo; ovos com um par de espinhos recurrentes convergentes e com um orifício recoberto por membrana entre eles.

Macho. Difere de S. brasilia pelos seguintes caracteres:

Coloração: Fronte castanho-escura, com exceção de uma faixa castanho-clara ao redor da lúnula, tocando a extremidade do triângulo ocelar, que tem a mesma coloração da fronte; faciália dourada; escapo amarelo; pedicelo e flagelo castanhoclaros (Figs. 31, 32); lobos pós-pronotais amarelos; notopleura amarela com uma protuberância castanho-escura na região mediana; escuto castanho-escuro, com mancha castanho-clara posterior (Fig.33); pernas metatorácicas castanhas, com três faixas amarelas transversais nos fêmures; tergito 1 castanho na região dorsal, amarelo na região próxima à pleura; tergito 2 , 3 e 4 com área castanha em forma de $T$ dorsal e laterais amarelas; tergito 5 inteiramente castanho. Cabeça: Triângulo ocelar com a extremidade anterior pontiaguda; protuberâncias frontais muito pouco pronunciadas; pedicelo com pilosidade um pouco maior que a do flagelo; cerdas genais claras (Figs. 31, 32). Tórax: Cerda proepisternal clara; asas com $\mathrm{M}_{1+2}$ suavemente curva, encontrando $\mathrm{R}_{4+5}$ bem próximo ao ápice (Fig.34). Abdome: Tergito $1 \mathrm{com}$ um conjunto de cerdas pretas na margem ventral; esternitos totalmente membranosos; esternitos 4 e 5 com cerdas pretas dirigidas para trás na margem posterior, o esternito 5 com protuberância centro-marginal em forma de Y (Fig. 35). Terminália: Sintergosternito 6+7+8 com cerca de 1/ 3 da largura do epândrio em sua linha média dorsal; epândrio com cerdas fortes na margem posterior; cercos com algumas cerdas claras basais na margem posterior, ápice arredondado e dobrado para dentro; surstilos com dois lobos: o anterior com pequenas cerdas pretas na margem posterior e espinhos na face interna e o posterior com cerdas claras; parâmeros grandes, com abundantes cerdas pretas na margem posterior; edeago membranoso com duas projeções apicais anteriores e uma projeção arredondada mais curta posterior (Fig.36).

Fêmea. Semelhante ao macho, exceto pelos caracteres:

Coloração: Tergito 2 apenas com uma faixa amarela ventral e o restante inteiramente castanho; tergito 5 amarelo com faixa dorsal castanha, estendendo-se até cerca de metade da distância até a margem posterior do segmento; tergito 6 castanho na parte dorsal e amarelo na ventral; tergito 7 amarelo com mancha dorsal castanha; esternito 8 castanho com ápice amarelo; apêndices laterais do esternito 8 amarelos; cercos e placa subanal com o ápice castanho. Tórax: Fêmur posterior sem cerdas longas na face ventral. Abdome: Esternitos sem cerdas. Terminália: Esternito 8 com reentrância mediana ventral em forma de $\mathrm{V}$ e com algumas cerdas fortes no ápice, apêndices laterais com as pontas levemente curvas; cercos alongados e sinuosos, com cerdas pretas; placa subanal alongada e com cerdas pretas (Figs. 37, 38, 39).

Ovos. Escamas do cório com aspecto imbricado; espinhos laterais convergentes, com o ápice mais escuro; orifício entre o espinhos laterais recoberto por membrana e se estendendo pouco além das escamas (Figs. 40, 41).

Distribuição: Brasil (AC), Peru, Bolívia.

Material examinado: PERU: Madre de Dios, Avispas, 400 m., 2030.IX.1962, L. Peña, 1 macho parátipo (CNC); Cuzco, Quincemil, 780 m., 13-31.VIII.1962, L. Peña, 1 macho parátipo (CNC); idem, 700 m., 1-15.XI.1962, L. Peña, 1 macho e 1 fêmea parátipos (CNC)

\section{Stylogaster rafaeli Camras \& Parrillo, 1996}

(Figs. 42-47)

Stylogaster rafaeli Camras \& Parrillo, 1996: 223. Localidade-tipo: Brasil, Rondônia, Ariquemes, rio Ji-Paraná. Holótipo macho (INPA).

Diagnose: Cerdas verticais fortemente inclinadas para trás; asas com cílios costais grandes e eretos; cerdas presentes na região do esternito 4 do macho; esternito 5 do macho apresentando uma protuberância na margem posterior, com um tufo de cerdas longas, voltadas para a frente; terminália do macho apresentando edeago com quatro projeções: duas mediais dirigidas para frente e duas apicais.

\section{Macho. Difere de S. brasilia por apresentar:}

Coloração: Fronte castanho-escura com faixa mais clara ao redor da lúnula; triângulo ocelar com polinosidade prateada e protuberância castanho-escura entre os ocelos (Fig. 42); faciália com polinosidade dourada; probóscide preta, com ápice, base e labelos amarelos; escapo amarelo; pedicelo pouco mais escuro que o escapo; flagelo castanho-claro, com mancha castanho-escura na região de inserção da arista (Fig. 43); notopleura castanho-clara até a altura da sutura; escuto castanho-escuro com manchas claras laterais pré-suturais e com uma faixa longitudinal mediana pouco mais clara; escutelo castanho-escuro; anepisterno castanho em sua porção dorsal (Fig.44); halter com base amarela e ápice castanho-escuro (Fig.44); pernas anteriores e médias com tarsos amarelos no ápice e castanhos na base, com cerdas seguindo o mesmo padrão de coloração; perna posterior com coxa castanha, fêmur castanho-claro, com duas faixas transversais castanho-escuras, tíbia castanho-clara com ápice castanho-escuro, e tarso castanho-escuro; tergito 1 castanho dorsalmente, laterais e margem posterior amarelas; tergito 5 castanho com mancha amarela estendendo-se da margem anterior até pouco mais de metade do segmento; sintergosternito $6+7+8$ com metade anterior amarela e a metade posterior castanha. Cabeça: Triângulo ocelar com extremidade pontiaguda; protuberâncias 


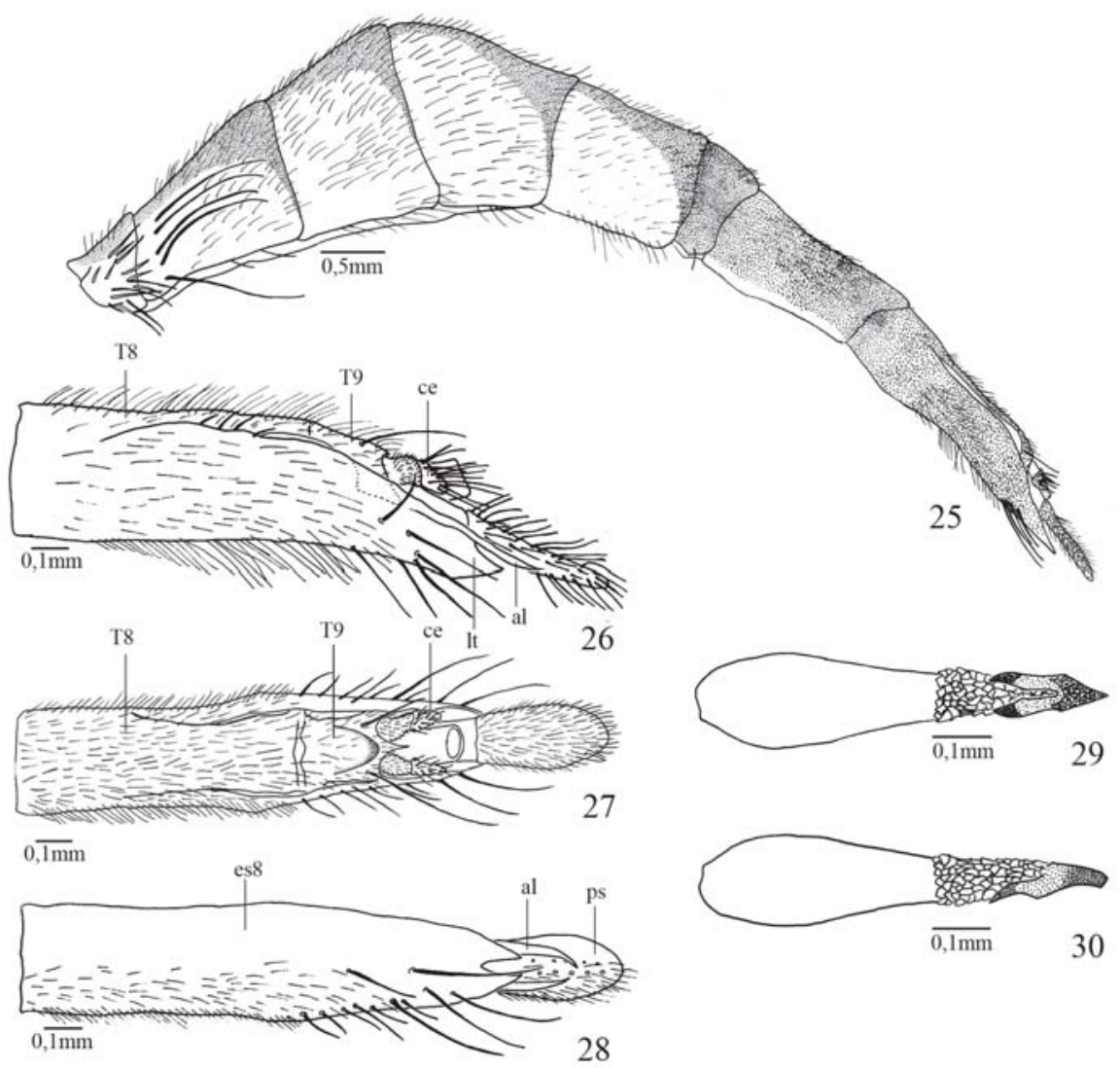

Fig. 25. Stylogaster fluminensis sp. nov. abdome, fêmea, vista lateral; fig. 26: terminália feminina, vista lateral; fig. 27: terminália feminina, vista dorsal; fig. 28: terminália feminina, vista ventral; fig. 29: ovo, vista ventral; fig. 30: ovo, vista lateral (al= apêndice lateral do esternito 8; ce= cerco; es= esternito; $1 \mathrm{t}=$ lobo lateral do esternito $8 ; \mathrm{ps}=$ placa subanal; $\mathrm{T}=$ tergito) .

frontais muito pequenas; cerdas pós-oculares diferenciadas; pedicelo com cerdas na superfície dorsal e na margem (Figs. 42, 43). Tórax: Cerda proepisternal clara; pernas anteriores e médias com cerdas pretas em toda a extensão dos fêmures, exceto na face ventral, e cerdas claras nas tíbias; tíbia anterior com esporão claro; perna posterior apresentando coxa com cerdas na face anterior, trocânter com longas cerdas pretas na face posterior, fêmur e tíbia com cerdas pretas, sem esporões. Asas com cílios costais relativamente grandes e eretos; curvatura de $\mathrm{M}_{1+2}$ relativamente suave, encontrando-se com $\mathrm{R}_{4+5}$ bem próximo da veia costal (Fig.45). Abdome: Tergito 1 com uma protuberância na margem anterior onde se inserem algumas cerdas pretas; esternito 5 apresentando grande quantidade de cerdas longas, formando um tufo característico (Fig.46); esternitos 1-4 membranosos e com pilosidade apenas a partir do esternito 4. Terminália: Sintergosternito $6+7+8 \mathrm{com}$ cerdas pretas e com um sulco na região mediana; epândrio com cerdas pretas em toda a extensão; cercos com cerdas pretas posteriores, ápice nu, arredondado e dobrado; surstilos com dois lobos: $\mathrm{o}$ anterior com pequenos espinhos pretos em toda a extensão e o posterior com cerdas claras e poucas cerdas pretas entremeadas; parâmeros com cerdas curtas, fortes e numerosas; edeago esclerosado, com área basal escura e endofalo esclerosado, e com quatro projeções: duas medianas dirigidas para frente e duas apicais pontigudas (Fig.47).
Fêmea e ovo: desconhecidos. Distribuição: Brasil (RO).

Material examinado: BRASIL: Rondônia, Ariquemes, rio Ji-Paraná, 0944'S-6152'W, 28.X.1986, J. A. Rafael (Malaise), holótipo macho e 2 machos parátipos (INPA).

\section{Stylogaster souzai Monteiro, 1960}

(Figs. 48-53)

Stylogaster souzai Monteiro, 1960: 111. Localidade-tipo: Brasil, Amapá, Mazagão, "do Jari ao Vila Nova". Holótipo macho (MNRJ). Ref. Papavero 1971; Camras \& Parrillo 1985, 1996.

Diagnose: Pedicelo maior que o flagelo; tíbias médias com esporões claros; asa com veia $\mathrm{A}_{2}$ fraca; machos com esternito 5 apresentando leve reentrância na margem posterior e com cerdas esparsas apenas na margem.

Macho. Difere de S. brasilia pelos seguintes caracteres:

Coloração: Fronte castanho-escura, exceto na região próxima à lúnula; faciália dourada; probóscide preta com ápice e base amarelos; flagelo castanho, mais claro na base que no ápice; notopleura castanha com região amarela que se estende até a sutura; escuto castanho com três faixas claras longitudinais, uma anterior e duas posteriores à sutura (Fig. 

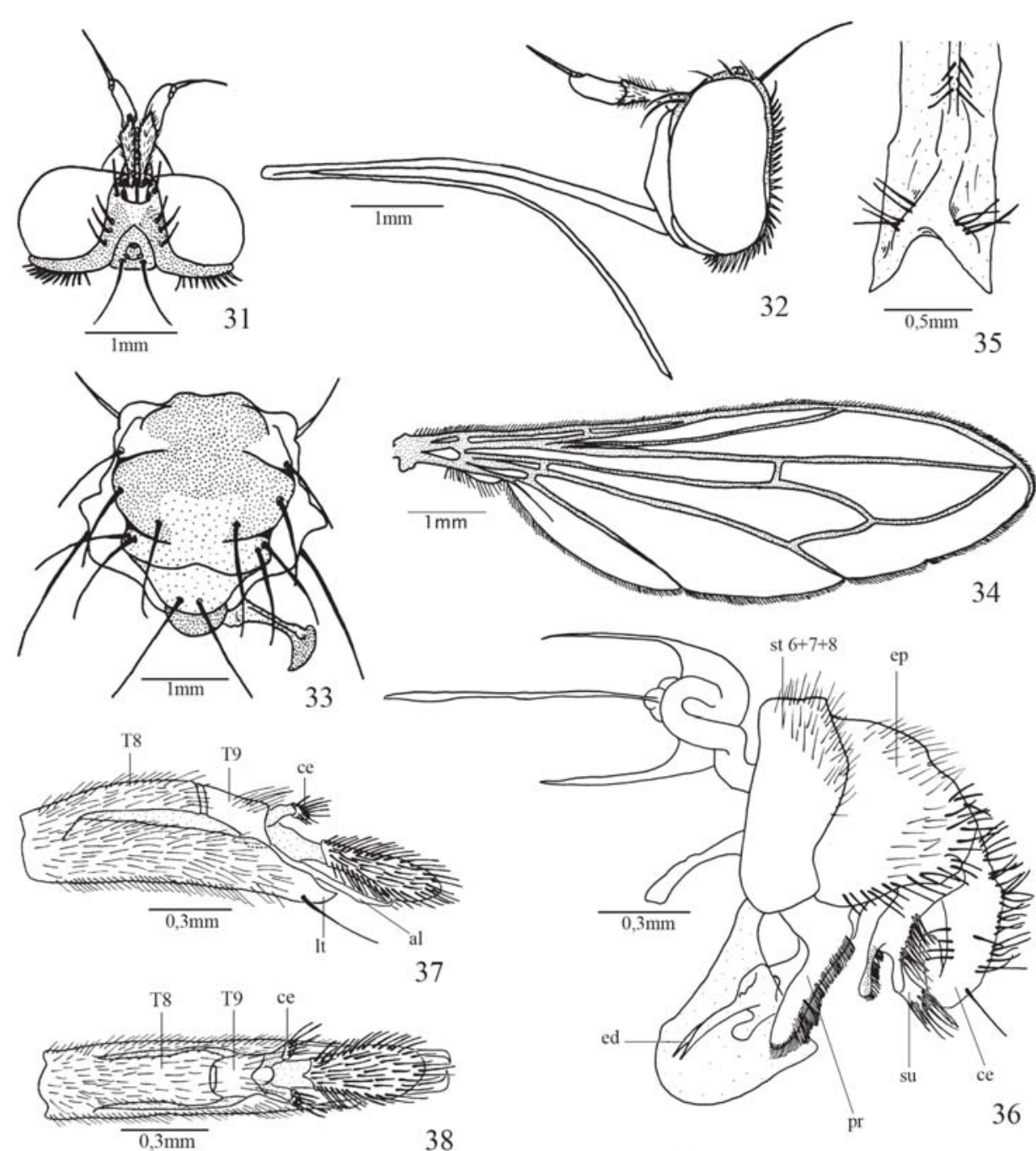

\section{8}
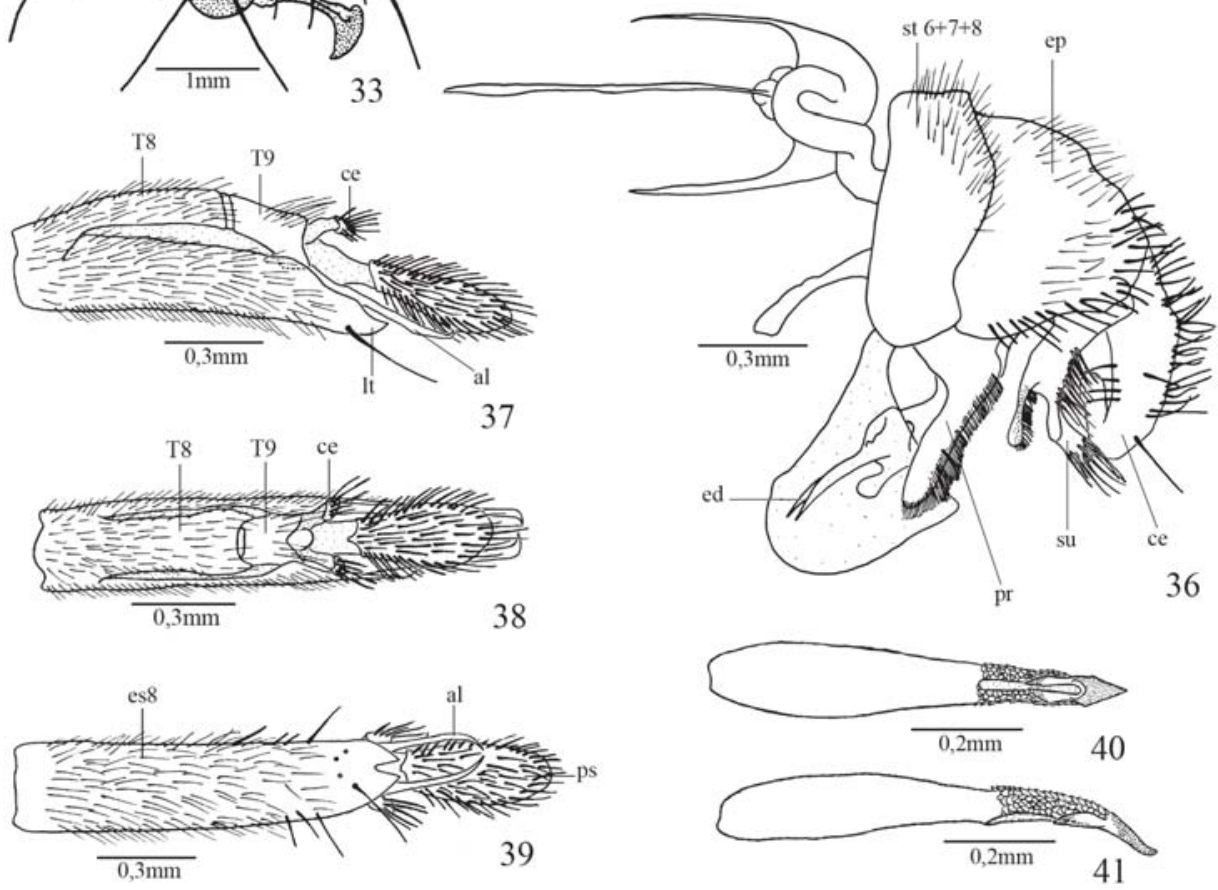

Fig.31. Stylogaster longispina Camras \& Parrillo. cabeça, macho, vista dorsal; fig.32: cabeça, macho, vista lateral; fig.33: macho, tórax, vista dorsal; fig. 34: asa; fig. 35: esternito 5, macho; fig. 36: terminália masculina, vista lateral; fig. 37: terminália feminina, vista lateral; fig.38: terminália feminina, vista dorsal; fig. 39: terminália feminina, vista ventral; fig. 40: ovo, vista ventral; fig. 41: ovo, vista lateral (al= apêndice lateral do esternito 8; ce= cerco; $\mathrm{ed}=$ edeago; $\mathrm{ep}=$ epândrio; es= esternito; lt= lobo lateral do esternito 8 ; pr= parâmero; ps= placa subanal; st= sintergosternito; su= surstilo; $\mathrm{T}=$ tergito).

50); escleritos pleurais amarelos; halter com a base amarela e ápice castanho (Fig. 50); tergito 2 castanho com margem anterior clara; tergitos 3 e 4 castanhos com manchas laterais amarelas; tergito 5 castanho com pequena mancha amarela látero-basal; sintergosternito $6+7+8$ castanho com polinosidade prateada e margem anterior amarela; epândrio com faixa amarela lateral (Fig. 53). Cabeça: Triângulo ocelar com ápice pontiagudo; cerdas pós-oculares diferenciadas; pedicelo maior que o flagelo e com cerdas pretas em toda extensão (Figs. 48, 49). Tórax: Cerda proepisternal clara; pernas apresentando tíbia média com esporão claro; asas com veia $\mathrm{A}_{2}$ fraca, porém visível (Fig.51). Abdome: Tergito 1 com uma série de cerdas claras e pretas; esternitos 1-4 membranosos, sem pilosidade; esternito 5 com poucas cerdas pretas apicais (Fig. 52). Terminália: Sintergosternito $6+7+8$ com cerca de $1 / 3$ da largura do epândrio em sua linha média dorsal; sintergosternito e epândrio com ambas as cerdas, pretas e claras; cercos com projeção posterior perto da base e com cerdas pretas dirigidas para trás; surstilos com numerosas cerdas claras no lobo posterior e com pequenos espinhos pretos na face interna do lobo anterior; 

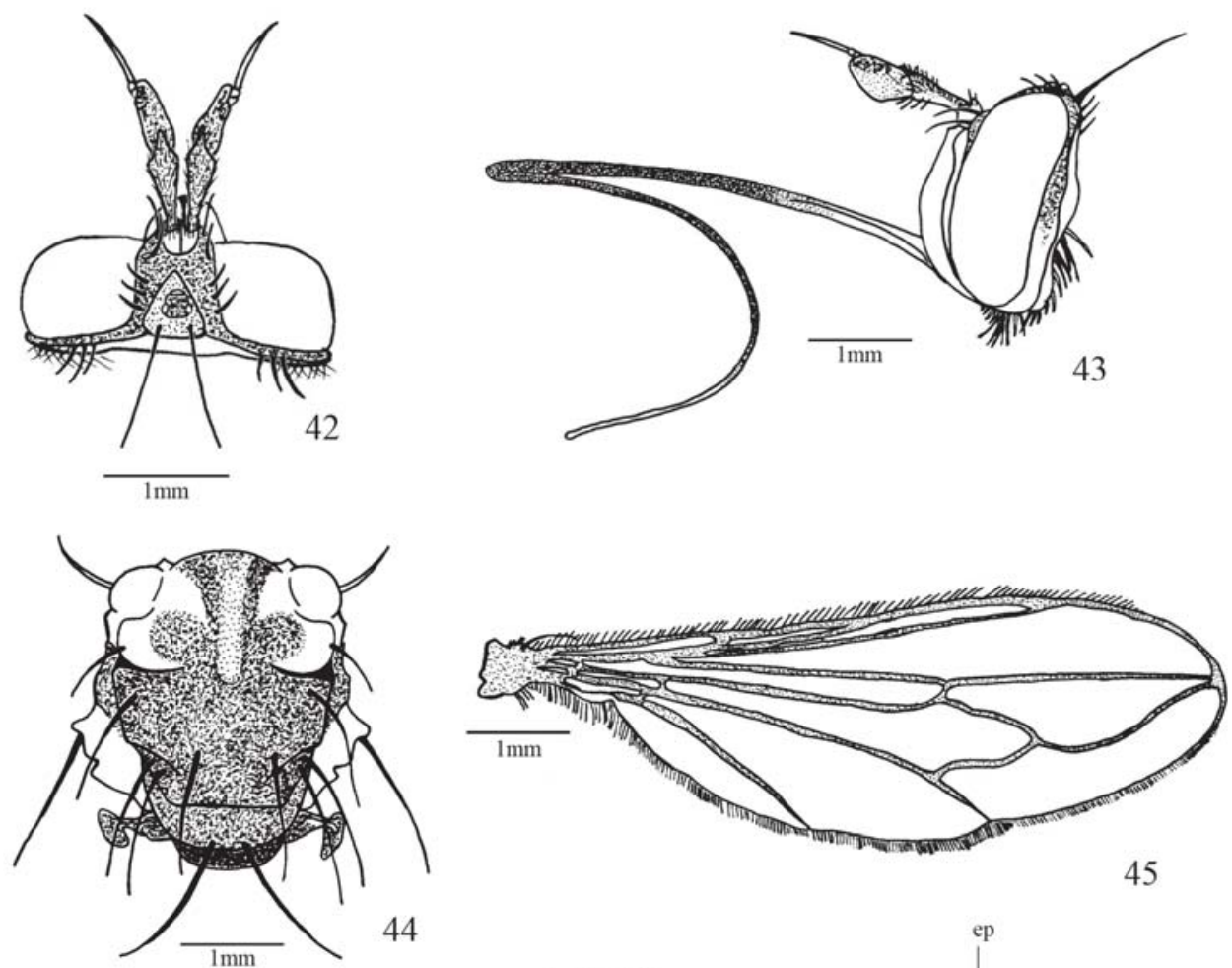

45

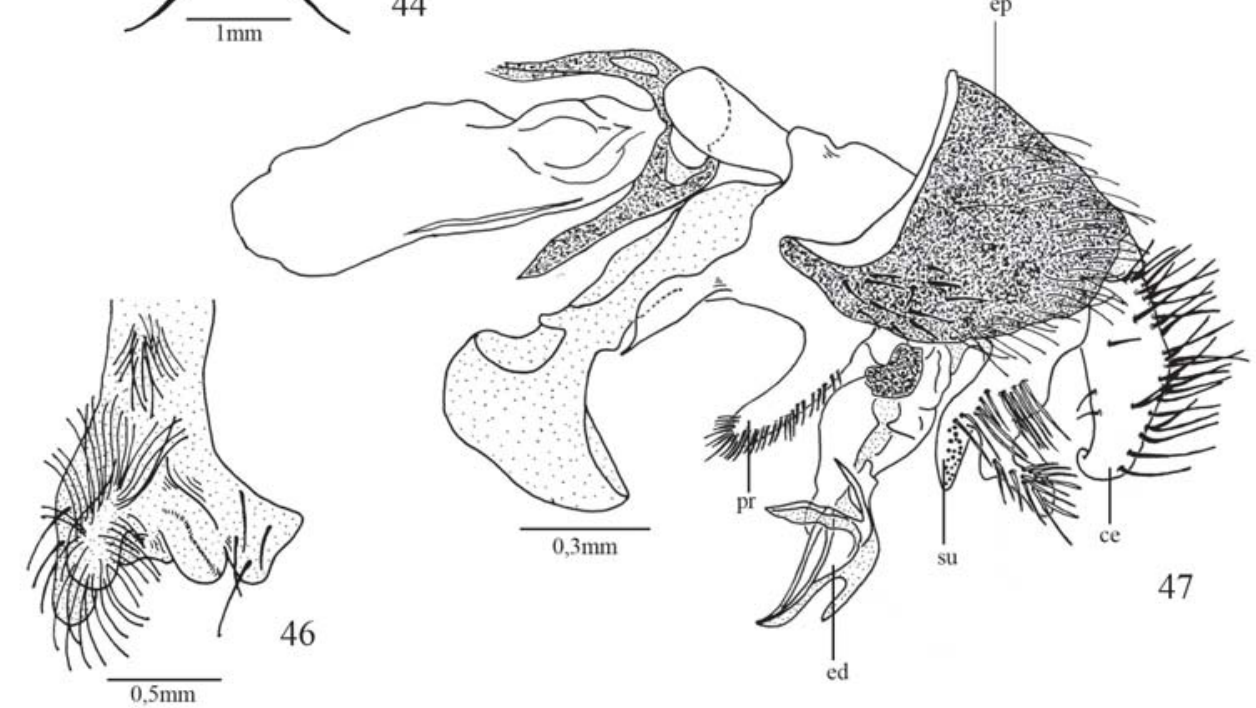

Fig. 42. Stylogaster rafaeli Camras \& Parrillo. cabeça, macho, vista dorsal; fig. 43: cabeça, macho, vista lateral; fig. 44: macho, tórax, vista dorsal; fig. 45: asa; fig. 46: esternito 5, macho; fig. 47: terminália masculina, vista lateral $(c e=$ cerco; ed= edeago; ep= epândrio; pr= parâmero; su= surstilo).

parâmeros com numerosas cerdas marginais; edeago esclerosado, com uma área oval quase negra próximo à base, canais internos mais escurecidos e duas projeções apicais, agudas e membranosas (Fig. 53).

Fêmea e ovo: desconhecidos.

Distribuição: Brasil (AP, PA).

Material examinado: BRASIL: Amapá, Mazagão, Jari ao V. Nova, 1958, Damasceno, holótipo macho (MNRJ); Pará, Oriximiná, Rio Trombetas, Alcoa Miner, Monte Branco, 07.X.1982, J. A. Rafael (Malaise), 1 macho parátipo (INPA).

\section{Stylogaster stylata (Fabricius, 1805) \\ (Figs. 54-60)}

Conops stylatus Fabricius, 1805: 177. Localidade-tipo: "América do Sul”. Holótipo macho (ZMUC). Ref. - Lopes, 1937.

Stylogaster stylata, Macquart, 1835: 39. Localidade-tipo: “América do Sul”. Ref. - Lopes 1937; Monteiro 1960; Papavero 1971; Camras \& Parrillo 1985, 1996; Kotrba 1997; Mello-Patiu \& Rocha 2003. Stylogaster argentina Kröber, 1929: 174. (como biannulata var.). Localidade-tipo: Argentina, Tapikiolé.

Diagnose: Arista com dois artículos no macho (Fig. 54) e 

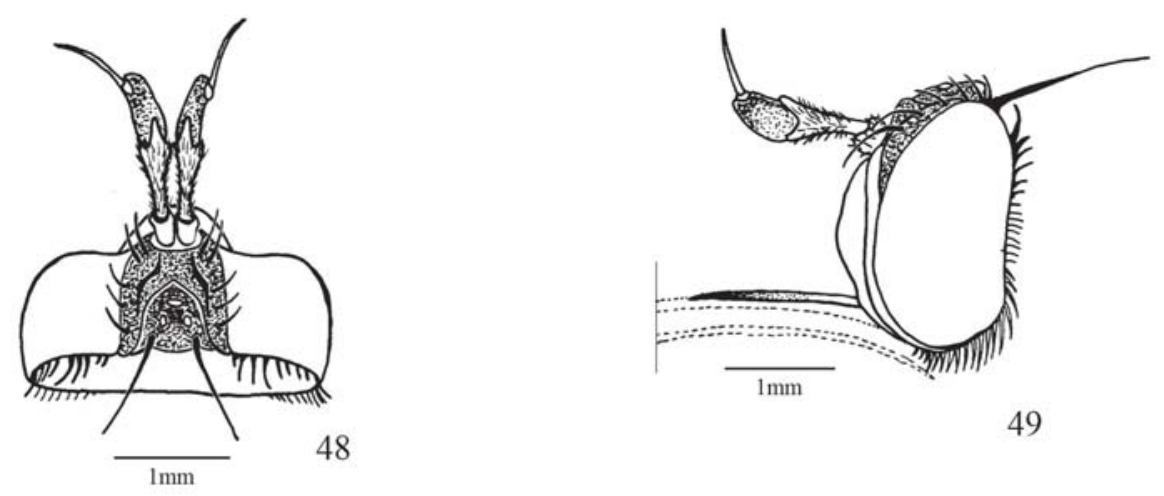

49

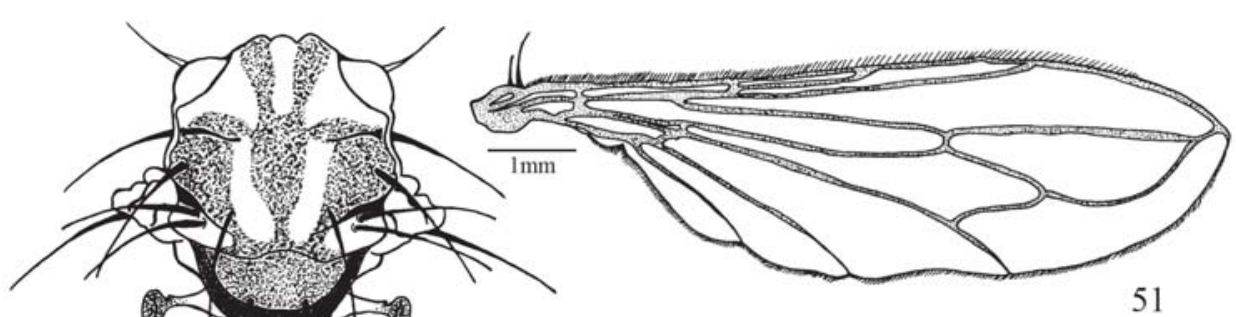

51
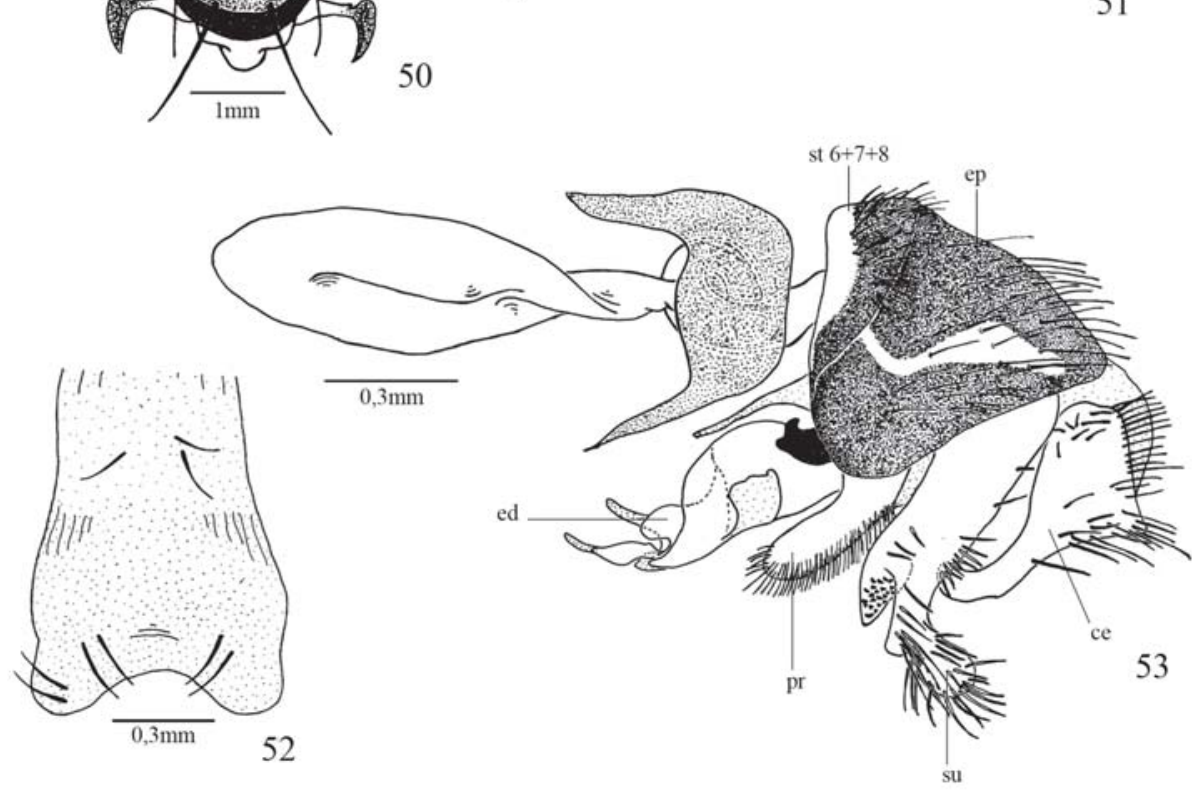

Fig. 48. Stylogaster souzai Monteiro. cabeça, macho, vista dorsal; fig. 49: cabeça, macho, vista lateral; fig. 50: macho, tórax, vista dorsal; fig. 51: asa; fig. 52: esternito 5, macho; fig. 53: terminália masculina, vista lateral $(c e=$ cerco; ed= edeago; ep= epândrio; $p r=$ parâmero; st= sintergosternito; $\mathrm{su}=$ surstilo).

um na fêmea (Fig. 55); coxas anteriores com cerdas claras nas faces anterior e posterior; cerda proepisternal clara; esternito 5 do macho com reentrância na margem posterior e com cerdas pretas em toda a extensão (Fig. 56); terminália do macho apresentando o sintergosternito $6+7+8$ com cerca de $1 / 3$ da largura do epândrio em sua linha média dorsal; cercos fortemente dobrados para dentro, se entrecruzando, com cerdas pretas na face externa e cerdas claras na face interna, surstilos com dois lobos, $\mathrm{o}$ anterior com cerdas espiniformes pretas e o posterior dobrado e coberto por longas cerdas claras (Fig. 57); terminália da fêmea apresentando esternito 8 com profunda reentrância mediana ventral, dois lobos terminais laterais (Figs.
$58,59)$ e apêndice lateral pouco esclerosado em forma de gancho (Fig. 58); ovos com extremidade anterior afilada e naviforme (Fig. 60).

Distribuição: Brasil (AP, PA, MT, RJ, SC), Equador, Colômbia, Paraguai, Argentina.

Material examinado: BRASIL: Rio de Janeiro, Rio de Janeiro, Represa do Rio Grande [Floresta da Tijuca], VI.1967, M. Alvarenga (Malaise), 2 machos e 1 fêmea (MNRJ); Santa Catarina, Nova Teutônia, $27^{\circ} 11^{\prime}$ S $-52^{\circ} 23^{\prime}$ W, XI.1959 e II.1961, Fritz Plaumann, 2 machos (MNRJ); idem, XII.1959, X.1960 e III.1961, 3 fêmeas (MNRJ).

Comentários: Stylogaster stylata (Fabricius, 1805) foi 

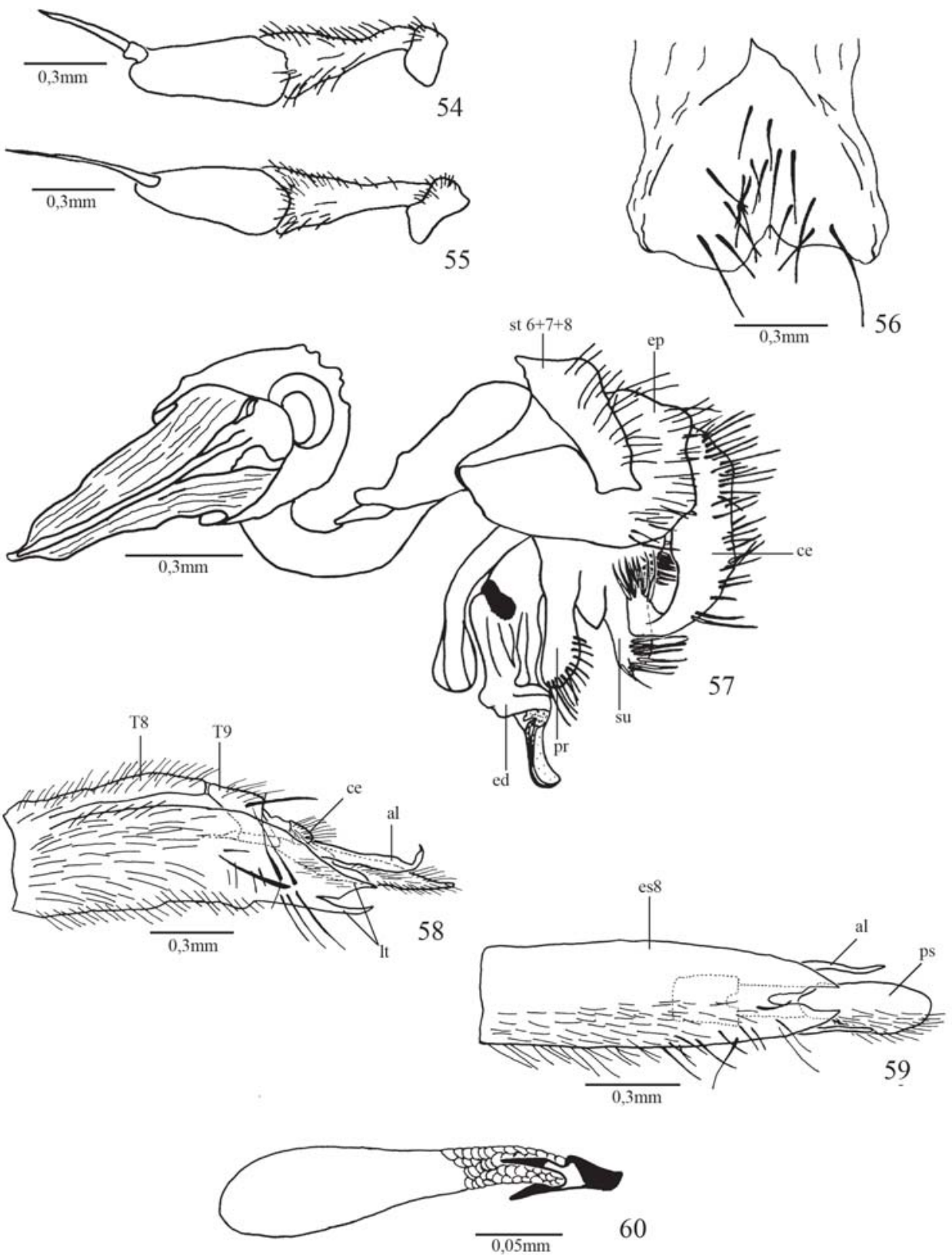

Fig. 54. Stylogaster stylata (Fabricius). antena, macho; fig. 55: antena, fêmea; fig. 56: esternito 5, macho; fig. 57: terminália masculina, vista lateral; fig. 58: terminália feminina, vista lateral; fig. 59: terminália feminina, vista ventral; fig. 60: ovo, vista látero-ventral (al= apêndice lateral do esternito 8 ; $\mathrm{ce}=$ cerco; $\mathrm{ed}=$ edeago; $\mathrm{ep}=$ epândrio; es= esternito; $1 \mathrm{t}=$ lobo lateral do esternito 8 ; pr= parâmero; $\mathrm{ps}=\mathrm{placa}$ subanal; $\mathrm{st}=$ sintergosternito; su= surstilo; $\mathrm{T}=$ tergito).

redescrita e revista em detalhe por Mello-Patiu \& Rocha (2003), com ilustrações de cabeça, tórax, abdome, terminália do macho e da fêmea, e ovo. Foi considerada morfologicamente mais próxima a S. stylosa Townsend, 1897, por apresentar cerdas claras nas faces anterior e posterior das coxas anteriores e esternito 5 do macho com reentrância na margem posterior.

\section{Stylogaster stylosa Townsend, 1897}

(Figs. 61-74)

Stylogaster stylosa Townsend, 1897: 27. Localidade-tipo: México,
Veracruz, Rio Nautla. Síntipos (BMNH). Ref. - Lopes 1937 (erro identificação); Papavero 1971; Camras \& Parrillo 1985.

Diagnose: Coxas anteriores do macho com cerdas claras e pretas; asa com $\mathrm{M}_{1+2}$ encontrando-se com $\mathrm{R}_{4+5}$ antes do ápice; esternito 5 do macho com cerdas claras longas dirigidas para trás e profunda reentrância mediana na margem posterior; terminália da fêmea com cercos fundidos na base.

Macho. Difere de S. brasilia por apresentar:

Coloração: Fronte castanho-escura na metade superior e castanho-clara até a lúnula; triângulo ocelar castanho-claro, 

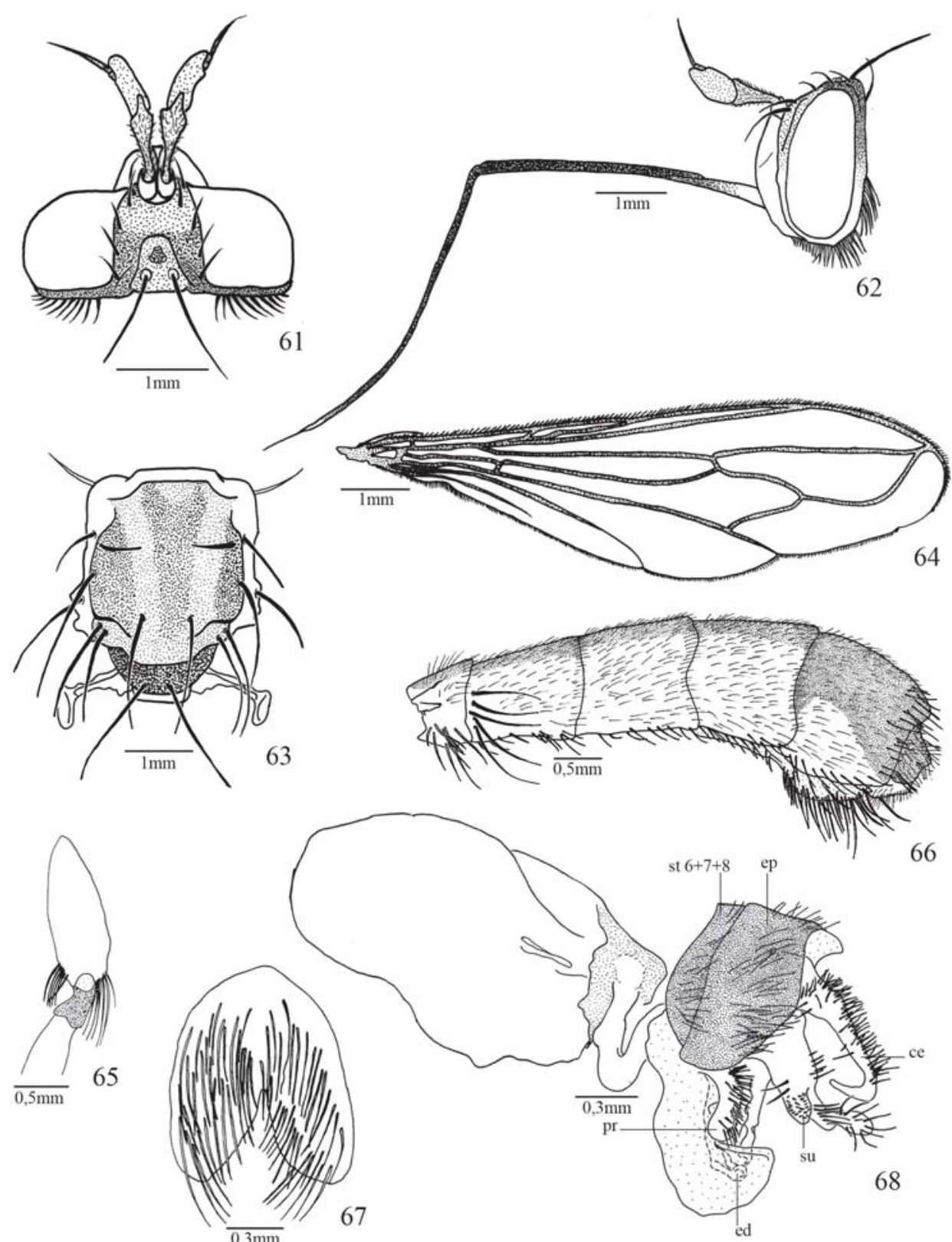

Fig. 61. Stylogaster stylosa Townsend. cabeça, macho, vista dorsal; fig. 62: cabeça, macho, vista lateral; fig. 63: macho, tórax, vista dorsal; fig. 64: asa; fig. 65: coxa e trocânter anteriores; fig. 66: abdome, macho, vista lateral, fig. 67: esternito 5, macho; fig. 68: terminália masculina, vista lateral $(\mathrm{ce}=$ cerco; $\mathrm{ed}=$ edeago; $\mathrm{ep}=$ epândrio; $\mathrm{pr}=$ parâmero; $\mathrm{st}=$ sintergosternito; su= surstilo).

com tubérculo castanho-escuro; escapo amarelo, pedicelo e flagelo castanho-claros (Figs. 61, 62); notopleura amarela; escuto castanho-escuro, com a margem posterior castanhoclara; escleritos pleurais amarelos; halter castanho-claro (Fig.63); coxas castanhas, o restante das pernas anteriores e médias amarelo; fêmur posterior com duas faixas castanhas transversais, tíbia posterior com o terço apical castanho; tergito 1 castanho dorsalmente; tergitos 2, 3 e 4 amarelos com faixa dorsal longitudinal castanha; tergito $5 \mathrm{com}$ a maior parte do dorso e da lateral castanhos (Fig. 66); sintergosternito 6+7+8 e epândrio castanhos. Cabeça: Triângulo ocelar com a ponta arredondada; primeiras cerdas pós-oculares diferenciadas; pós-oculares restantes, occipitais e genais claras; protuberâncias frontais bem desenvolvidas; pedicelo e flagelo de comprimentos semelhantes (Figs. 61, 62). Tórax: Cerda proepisternal clara; pernas apresentando coxa anterior com ambas as cerdas, claras e pretas; trocânter anterior muito desenvolvido (Fig. 65); tíbias anterior e média com esporões claros; asas com veia $\mathrm{R}_{4+5}$ encontrando-se com $\mathrm{M}_{1+2}$ acima do ápice; $\mathrm{M}_{1+2}$ fortemente curva; $\mathrm{A}_{2}$ fraca (Fig. 64). Abdome: Tergito 1 com cerdas ventrais claras e dorsais pretas (Fig. 66); esternito $5 \mathrm{com}$ cerdas claras longas dirigidas para trás, margens posteriores arredondadas e profunda reentrância mediana (Fig.67). Terminália: Sintergosternito $6+7+8$ com cerca 


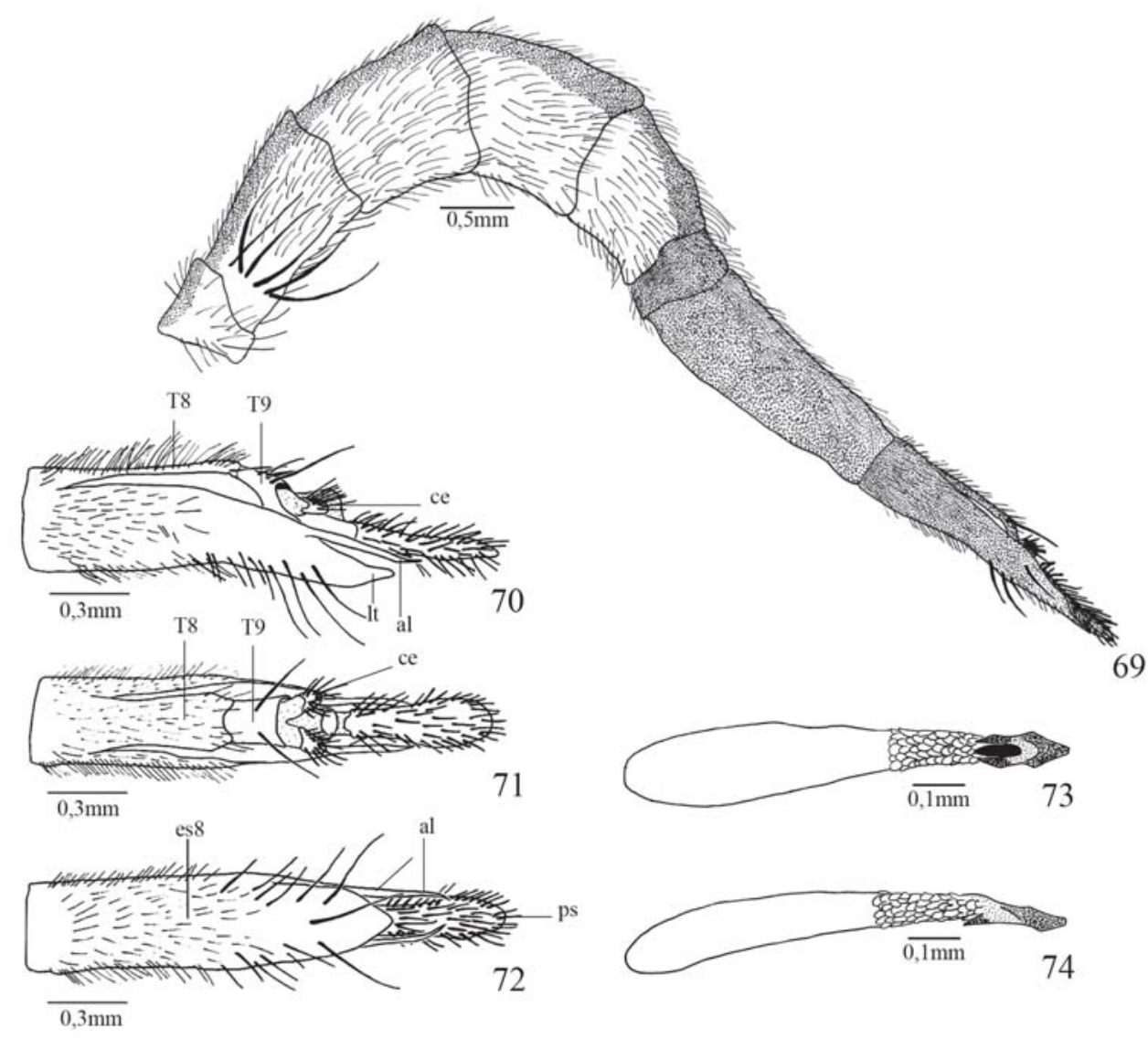

Fig. 69. Stylogaster stylosa Townsend. abdome, fêmea, vista lateral; fig. 70: terminália feminina, vista lateral; fig. 71: terminália feminina, vista dorsal; fig. 72: terminália feminina, vista ventral; fig. 73: ovo, vista ventral; fig. 74: ovo, vista lateral (al= apêndice lateral do esternito 8; ce= cerco; es= esternito; $1 \mathrm{t}=$ lobo lateral do esternito 8 ; ps= placa

de 1/3 da largura do epândrio em sua linha média dorsal; cercos finos, com cerdas pretas e claras e ápice curvo; surstilos apresentando lobo anterior com pequenas cerdas pretas na face interna e um par de cerdas pretas dirigido para a frente na face externa, e lobo posterior com uma série de cerdas claras e com cerdas pretas apicais; parâmeros curvos com numerosas cerdas pretas; edeago membranoso, sem projeções apicais (Fig. 68).

Fêmea. Semelhante ao macho, exceto pelos caracteres:

Coloração: Fronte castanho-escura em toda extensão; tergitos 6, 7 e esternito 8 castanho-escuros (Fig. 69). Tórax: Coxas anteriores somente com cerdas pretas; tíbias médias sem esporões e com cerdas alongadas em forma de pente na face inferior. Terminália: Tergito 6 estreito cerca de $1 / 4$ do comprimento do tergito 7 (Fig. 69); tergito 9 com 2 cerdas fortes; esternito 8 densamente piloso com ápice pontiagudo e sem reentrância e apêndices laterais com curvatura apical muito suave; cercos fundidos na base (Figs.70, 71, 72).

Ovo. Espinho posterior com a base alargada; espinhos recurrentes paralelos à margem do cório e com orifício entre eles (Figs. 73, 74).

Distribuição: E.U.A, México.
Material Examinado: MÉXICO: Veracruz, San Rafael; 3. 29. X. [3.X.1829?], Townsend, 2 machos e 2 fêmeas síntipos (BMNH).

\section{DISCUSSÃO}

O grupo stylata foi caracterizado por Camras \& Parrillo (1985) por apresentar ovipositor e triângulo ocelar curtos, à semelhança dos outros Conopidae, além da ausência de cerdas ocelares e pós-pronotais, e de possuir escapo e pedicelo com comprimentos similares entre si. Os autores se referiram ao grupo como sendo o "mais primitivo" dentre os quatro propostos, porém não utilizaram metodologia filogenética para inferir tal hipótese e apenas uma análise mais ampla do gênero poderá elucidar tal questão. Entretanto, ovipositor curto e triângulo ocelar curto são caracteres também encontrados em outros gêneros de conopídeos, como Conops Linnaeus e Physocephala Schiner. Por outro lado, os caracteres que distinguem o grupo stylata dos demais, como a forma do triângulo ocelar, os comprimentos relativos triângulo ocelar/ fronte e ovipositor/abdome, e a ausência da cerda póspronotal, são caracteres que ocorrem em um ou outro grupo de Stylogaster.

O exame do material-tipo de Stylogaster stylosa Townsend, 
1897 permitiu corroborar a hipótese de Camras \& Parrillo (1985), verificando-se que os espécimes identificados como S. stylosa procedentes do Rio de Janeiro não correspondem a esta espécie, tratando-se de uma espécie nova aqui descrita, Stylogaster fluminensis.

Todas as espécies analisadas nesse trabalho foram consideradas válidas e nenhum caso de sinonímia foi identificado. Todas apresentaram caracteres distintos, especialmente no esternito 5 e terminália do macho, que proporcionam uma identificação segura. Além disso, a morfologia da terminália feminina e do ovo também se mostrou bastante útil na segregação das espécies. Rocha \& MelloPatiu (2004) consideraram $S$. dispar mais semelhante morfologicamente à $S$. stylata e à $S$. rafaeli, porém, após este estudo foi possível verificar que $S$. dispar, S. longispina, $S$. rafaeli e $S$. fluminensis se mostram mais semelhantes, especialmente por compartilharem a presença de protuberância no esternito 5 do macho. As três últimas espécies ainda apresentam edeago com projeções agudas apicais e veias $\mathbf{M}_{1+2}$ e $\mathrm{R}_{4+5}$ encontrando-se bem próximo à margem da asa. Stylogaster brasilia e $S$. souzai apresentam caracteres ora compartilhados com S. stylata, ora com S. dispar, S. longispina e S. rafaeli.

Agradecimentos. A Jeff Cumming (CNC), José Albertino Rafael e Rosaly Ale-Rocha (INPA), e Nigel Wyatt (BMNH) pelo empréstimo do material. À Fundação Carlos Chagas Filho de Amparo à Pesquisa do Estado do Rio de Janeiro - FAPERJ (Proc.Nº E-26/110.239/2008) pelo auxílio. Aos revisores anônimos pelas excelentes sugestões.

\section{REFERÊNCIAS}

Aldrich, J. M. 1930: American two-winged flies of the genus Stylogaster Macquart. Proceedings of the United States National Museum 78: $1-27$.

Camras, S. 1957: Descriptions and records of Neotropical Conopidae (Diptera). Psyche 64: 9-16.

Camras, S. 1963. Notes on Neotropical Stylogaster (Diptera: Conopidae) Journal of the Kansas Entomological Society 40: 4-9.

Camras, S. 1965. Family Conopidae, p. 625-632. In: A. Stone; C. W. Sabrosky; W. W. Wirth; R. H. Foote \& J. R. Coulson (eds.). A catalog of the Diptera of America North of Mexico. Washington. Agricultural Research Service, USDA, 1696 p.

Camras, S. 1967. Notes on Neotropical Stylogaster (Diptera: Conopidae). Journal of the Kansas Entomological Society 40: 4-9.

Camras, S. 1989. A new species of Stylogaster (Diptera: Conopidae) with notes on some types. Entomological News 100: 79-80.

Camras, S. 1990. A new species of Stylogaster from Brazil (Diptera: Conopidae). Memórias do Instituto Oswaldo Cruz 84: 75.

Camras, S. 1992. New Neotropical Conopidae. Entomological News 103: 83-85.

Camras, S. 2004. New Conopidae from the Neotropical Region (Diptera). Entomological News 114: 86-90.

Camras, S. \& P. P. Parrillo. 1985. Review of the New World Stylogaster (Diptera Conopidae). Annals of the Entomological Society of America 78: 111-126.
Camras, S. \& P. P. Parrillo. 1996. New Stylogaster and ranges of Conopidae (Diptera) from the Brazilian and Bolivian Amazonia. Acta amazonica 25: 221-234.

Coquillett, D. W. 1910. The type-species of the North American genera of Diptera. Proceedings of the United States National Museum 37: 499-647.

Fabricius, J. C. 1805. Systema antliatorum secundum ordines, genera, species. C. Reichard, Brunsvigae [=Brunswick]. xiv + [15]-372+[1]+30 p.

Hennig, W. 1973. Diptera (Zweiflügler), p. 1-200. In: J. C. Helmcke; D. Starck \& H. Wermuth (eds.). Handbuch der Zoologie. Eine Naturgesichte der Stamme des Tierreiches, gegründet von Willy Kükenthal. 4(2) 2/31, Lief. 20. Berlin, Walter de Gruyter

Kotrba, M. 1997. Shoot or stab? Morphological evidence on the unresolved oviposition technique in Stylogaster Macquart (Diptera: Conopidae). Proceedings of the Entomological Society of Washington 99: 614-622.

Kröber, O. 1919. Katalog der Conopiden nebst Beschreibung der Gattungen und Bestimmungstabellen der Gattungen und Arten. Archiv freunde Naturges (A) 83 (8): 1-91, (9): 1-52.

Kröber, O. 1929. Die Ausbeute der Deutschen Chaco-expedition 1925/ 26 (Diptera) [XI-XII] Conopidae. Konowia 8: 170-193.

Lopes, H. S. 1937. Contribuição ao conhecimento do gênero "Stylogaster" Macquart, 1835 (Dipt.: Conopidae). Archivos do Instituto de Biologia Vegetal 3: 257-293.

Macquart, J. 1835. Histoire naturelle des insectes. Diptères 2. Paris. 703 p.

McAlpine, J. F. 1981. Morphology and terminology - adults. In: J. F. McAlpine; B. V. Peterson; G. E. Shewell; H. J. Teskey; J. R. Vockeroth \& D. M. Wood (Eds.). Manual of Nearctic Diptera. Vol. 1. Agriculture Canada Monograph 27: 9-63.

Mello-Patiu, C. A. \& L. S. G. Rocha. 2003. Redescrição de Stylogaster stylata (Fabricius, 1805) (Diptera, Conopidae) com ênfase na morfologia da terminália e do ovo. Arquivos do Museu Nacional 61: $215-220$.

Monteiro, L. 1960. Insecta Amapaensia. Diptera Conopidae: espécies do gênero Stylogaster Macquart, 1835. Memórias do Instituto Oswaldo Cruz 58: 103-114.

Papavero, N. 1971. Family Conopidae, p. 1-28. In: Papavero, N. (org.). A Catalogue of the Diptera of the America South of the United States, Vol. 47, São Paulo, Departamento de Zoologia, Secretaria de Agricultura.

Rocha, L. S. G. \& C. A. Mello-Patiu. 2004. Stylogaster dispar Camras \& Parrillo, 1985 (Diptera: Conopidae): Redescrição e morfologia, especialmente da terminália e do ovo. Anais da XIII Jornada de Iniciação Científica da UFRRJ 2003: 56-58.

Smith, K. G. V. \& B. V. Peterson. 1987. Conopidae. In: J. F. McAlpine; B. V. Peterson; G. E. Shewell; H. J. Teskey; J. R. Vockeroth \& D. M. Wood (Eds.). Manual of Nearctic Diptera. Vol. 2. Agriculture Canada Monograph 28: 749-756.

Townsend, C. H. T. 1897. Contributions to the New Mexico Biological Station. $\mathrm{N}^{\mathrm{o}}$ 2. On a collection of Diptera from the lowlands of the Rio Nautla, in the State of Vera Cruz. Annals and Magazine of Natural History 19: 16-34.

Westwood, J. O. 1852. Observations on the destructive species of dipterous insects known in Africa under the names of tsetse, zimb and tsaltsalya, and on their supposed connexion with the fourth plague of Egypt. Proceedings of the Zoological Society of London 18: 258-270.

Williston, S. W. 1883. North American Conopidae: Stylogaster, Dalmannia, Oncomyia. Transactions of Connecticut Academy of Arts and Sciences 6: 91-98.

Recebido em 25/11/2008; aceito em 15/10/2009 